\title{
Risk assessment and risk reduction of an acrylonitrile production plant
}

\author{
Kazuhiko Sano $^{\text {a, } *}$, Yusuke Koshiba ${ }^{\mathrm{b}}$, Hideo Ohtani ${ }^{\mathrm{c}}$
}

${ }^{\text {a }}$ Department of Risk Management, Graduate school of Environment and Information Sciences, Yokohama National University, 79-7 Tokiwadai, Hodogaya-ku, Yokohama 240-8501, Japan

${ }^{\mathrm{b}}$ Department of Materials Science and Chemical Engineering, Faculty of Engineering, Yokohama National University, 79-5 Tokiwadai, Hodogaya-ku, Yokohama 240-8501, Japan

${ }^{c}$ Department of Safety Management, Faculty of Environment and Information Sciences, Yokohama National University, 79-7 Tokiwadai, Hodogaya-ku, Yokohama 240-8501, Japan

* Corresponding author $\quad$ Telephone number: +819042023883

Fax number: +81 453393985

E-mail address: sano.kh@asahi-kasei.co.jp

Complete postal address: 79-7 Tokiwadai, Hodogaya-ku, Yokohama 240-8501, Japan

\begin{abstract}
Reducing accident occurrence in petrochemical plants is crucial, thus appropriately allocating management resources to safety investment is a vital issue for corporate management as international competition intensifies. Understanding the priority of safety investment in a rational way helps achieve this objective.

In this study, we targeted an acrylonitrile plant. First, Dow Chemical's Fire and Explosion Index (F\&EI) identified the reaction process as having the greatest physical risk. We evaluated the severity of accidents in the reaction process using the Process Safety Metrics advocated by the Center for Chemical Process Safety (CCPS); however, this index does not express damages a company actually experience. To solve this problem, we proposed a new metric that adds indirect cost to CCPS metrics. We adopted fault tree analysis (FTA) as a risk assessment method. In identifying top events and basic events, we attempted to improve the completeness of risk identification by considering accidents from the past, actual plant operation and equipment characteristics, natural disasters, and cyber-attacks and terrorist attacks. Consequently, we identified the top events with high priority in handling because of serious accidents as fire/explosion outside the reactor, fire/explosion inside the reactor, and reactor destruction. The new CCPS evaluation index proposed in this
\end{abstract}


study found that fire and explosion outside the reactor has the highest severity. We considered the creation of the fault tree (FT) diagram of the top event, estimating the occurrence probability, and identifying the risk reduction part and capital investment aimed at risk reduction. As an economically feasible selection method for risk reduction investment, using the difference in loss amounts before and after safety investments indicated investment priority.

Keywords: Acrylonitrile, Fire \& Explosion Index, Process Safety Metrics, fault tree analysis, risk identification, safety investment

\section{Introduction}

Petrochemical plants are complex technical systems with tightly coupled operation, equipment, and human factors and are places where accumulated technological know-how is applied. Unfortunately, serious accidents such as fires and explosions have occurred at petrochemical plants. Such accidents can be caused by various factors such as design and manufacturing defects, construction and inspection management failures, deficient operations standards and information transmission, insufficient technical prediction, aging facilities, or reduced personnel and maintenance.

When accidents or unexpected failures occur, it is sometimes said that there was some negligence. Therefore, engineers working in petrochemical plants must identify and reduce risks. Several methods risk prediction and analysis methods have been developed and have contributed to a reduction in accident-related fatalities and losses. For example, Baybutt (2018) reported that although risk management using a risk matrix is useful, there are pitfalls, and provided guidelines for constructing risk matrices that address these pitfalls. Cox (2008) reported that flaws have been identified in the underlying theoretical framework of risk matrices. Additionally, Curcurù et al. (2013) developed an imprecise fault tree analysis (FTA) method to characterize systems affected by a lack of reliability data. They estimated rate of occurrence of the top event, not probability of occurrence. Ferdous et al. (2009) reported on methodology for a fuzzy-based computer-aided FTA tool. Their goal was to handle cases in which the overall result may be questionable because of imprecise basic failure data. There has also been a lot of study on the Hazard and Operability Study (HAZOP), which is the standard for process risk analysis in the chemical process industry. To assist HAZOP, Kang et al. (2016) introduced sensitivity evaluation into HAZOP deviation analysis to measure the effect degree of each cause on the corresponding deviation. Guo et al. (2015) proposed an extended HAZOP analysis approach using a dynamic fault tree (FT) to identify potential hazards in chemical plants. Although intended as a study to supplement the insufficiency of HAZOP, MacGregor (2017) proposed a unique method merging HAZOP with failure mode and effects analysis (FMEA). As studies on combinations of risk assessment, in addition to Guo et al. (2015), studies have combined quantitative risk assessment, FTA, and severity analysis (e.g. Abuswer et al., 2013). Moreover, AlSharrah et al. (2007) proposed a risk index for the chemical processing industry consisting of four terms: accident frequency, hazardous effects of chemicals, inventory of chemicals released, and plant size.

Despite progress from the above studies, serious accidents still occur at petrochemical plants, some of which should not have happened based on the results of these studies. Furthermore, analysis of annual numbers of accidents in Japan shows that accident frequency is not decreasing at a sufficient rate. These facts appear to 
suggest the need to introduce new measures in addition to conventional measures to further reduce accidents and failures.

Many companies in Japan have identified issues that are considered factors leading to accidents, such as deteriorating industrial safety technology capabilities, aging of facilities, reduced capital investment and maintenance spending due to cost reduction requests, and decreased numbers of personnel with industrial safety skills. Any measure to address these issues will require additional costs in personnel, time, or money.

Accident reduction-related investments should be made for economically effective projects, and risk reduction effects should be evaluated based on comprehensive and ongoing risk assessment as well as from an appropriate management resource allocation perspective.

In this study, we focus on acrylonitrile (AN) plants and suggest a method for selecting economically feasible risk reduction method investments. We chose AN plants because the AN production process involves a gas phase partial oxidation reaction, which poses high risks. Additionally, AN has been suspected to be a carcinogen and have reproductive as well as general toxicity; therefore, risk management involves physical, environmental, and health risks. Few studies have been conducted on methods for estimating risks associated with AN plant industrial accidents, meaning that the findings of this study will be crucial for preventing accidents at AN plants.

In this study, to reduce fire/explosion risks in AN plants, we aimed 1) to identify high-risk parts of the AN production process, 2) assess risks in those parts, 3) establish a new technical system and protective measures to prevent fire/explosion accidents, and 4) propose a new method for selecting safety-related investment priorities based on a cost-to-benefit analysis.

\section{AN Production Process}

AN is produced from propylene and ammonia, and the main by-products are acetonitrile and hydrogen cyanide (see reaction formulae). Van der Bann (1980) developed an ammoxidation reaction to convert propylene to AN and showed that it is a first-order reaction propylene concentration reaction. The AN production process flow is shown in Fig.1.

$\begin{array}{llllll}\mathrm{CH}_{2}=\mathrm{CHCH}_{3}+\mathrm{NH}_{3}+3 / 2 \mathrm{O}_{2} & \rightarrow & \mathrm{CH}_{2}=\mathrm{CHCN} & +3 \mathrm{H}_{2} \mathrm{O} & : \text { Acrylonitrile } \\ \mathrm{CH}_{2}=\mathrm{CHCH}_{3}+3 / 2 \mathrm{NH}_{3}+3 / 2 \mathrm{O}_{2} & \rightarrow & 3 / 2 \mathrm{CH}_{3} \mathrm{CN} & +3 \mathrm{H}_{2} \mathrm{O} & : \text { Acetonitrile } \\ \mathrm{CH}_{2}=\mathrm{CHCH}_{3}+3 \mathrm{NH}_{3}+3 \mathrm{O}_{2} & \rightarrow & 3 \mathrm{HCN} & +6 \mathrm{H}_{2} \mathrm{O} & : \text { Hydrogen cyanide }\end{array}$

A catalyst with both suitable chemical activity and physical properties (e.g., abrasion resistance, particle size distribution, specific surface area, apparent density, catalyst shape, etc.) is employed in a fluidized bed reactor. Several papers have reported on catalyst compositions and production methods from with respect to improving AN production yield (Centi et al., 1998; Grasselli, 1986; Grasselli, 1999; Thanh-Binh et al., 2016). Additionally, many patents related to catalyst reactions have also been found. From a viewpoint of improving equipment, Dutta et al. (1999) focused on remodeling the reactor 
and reported on attaching a dispersion plate and improving flow characteristics to prevent gas drift in the catalyst layer. Maccallion (1996) investigated cyclone types to improve catalyst recovery rates. Reaction conditions vary depending on the catalyst used and reactor structure and are summarized in Table 1.

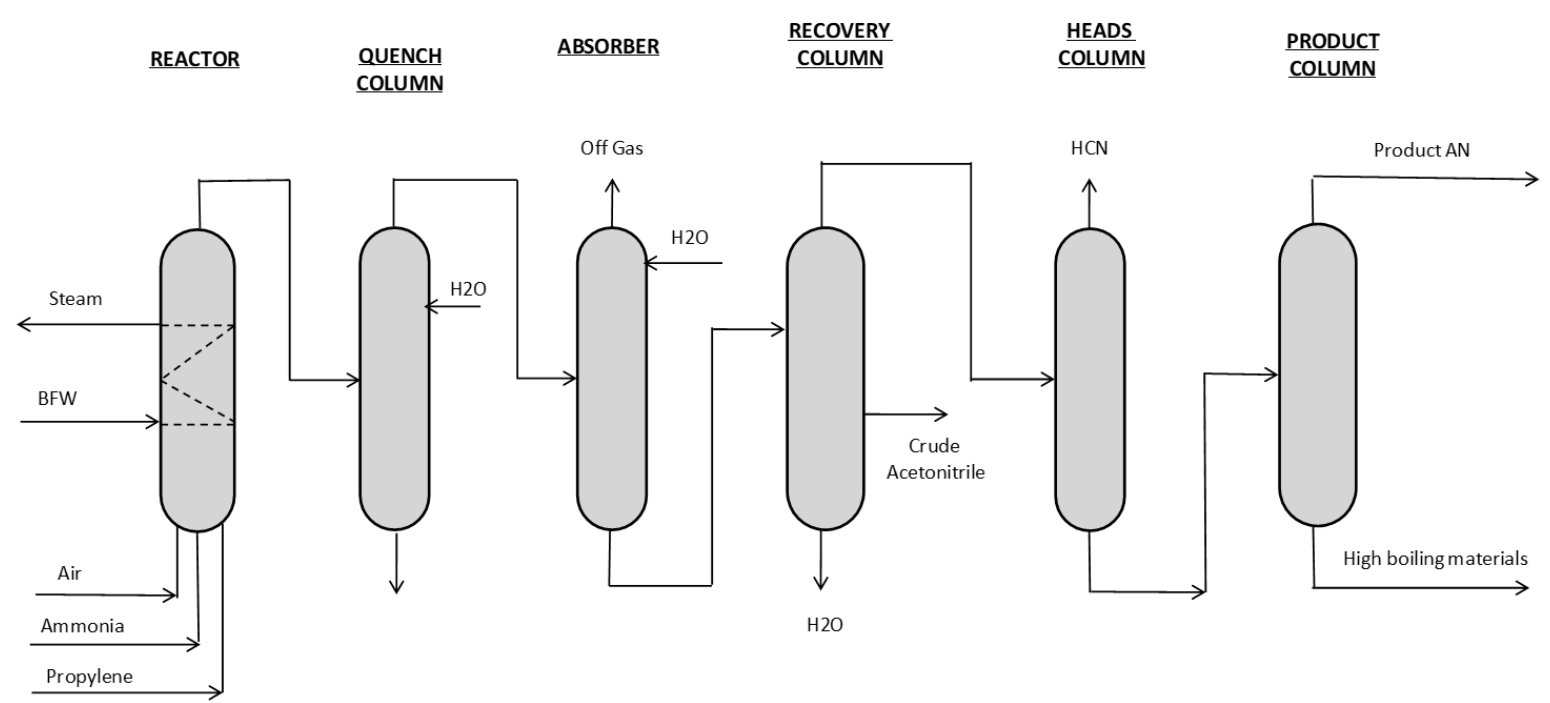

Fig. 1 AN Process Flow.

Table 1 Condition for acrylonitrile (AN) synthesis.

\begin{tabular}{lcc}
\hline Feed gas molar ratio & & $\mathrm{C} 3 \mathrm{H} 6: \mathrm{NH} 3:$ Air \\
& & $=1: 1.0-1.2: 9-12$ \\
\hline Reaction temperature & ${ }^{\circ} \mathrm{C}$ & $400-500$ \\
\hline Reaction pressure & $\mathrm{MPaG}$ & $0.05-0.15$ \\
\hline Linear velocity & $\mathrm{m} / \mathrm{s}$ & $0.4-1.0$ \\
\hline Contact time & $\mathrm{s}$ & $2-10$ \\
\hline
\end{tabular}

Ammoxidation is an exothermic reaction, and cooling coils in the reactor recover the reaction heat as steam, which is effectively used in the plant with the excess exported outside. From the perspectives of controlling the reaction and improving operational efficiency, research exists that focuses on enabling timely reaction condition adjustment through online analysis of the reaction product gas without requiring manual analysis (Goodrich, 1972). Hawkins et al. (1999) reported that fluidized bed reactors can be controlled using multivariate statistical process analysis by predicting changes in output due to input variable variations.

Product gases from the reactor are washed and cooled using an aqueous sulfuric acid solution in the quench column. After this, substances with high boiling points and unreacted ammonia in the product 
gas are then separated and removed. Ammonium sulfate generated from unreacted ammonia and sulfuric acid is then recovered as either ammonium sulfate or sulfuric acid.

Products such as AN, hydrogen cyanide, and acetonitrile in outlet gas at the quench column are absorbed using water in the absorber to form an aqueous solution, which is then withdrawn from the bottom of the absorber. In contrast, non-condensable gases, which are water-insoluble, are discharged from the top of the column and incinerated in a waste gas incinerator.

Because the boiling points of $\operatorname{AN}\left(77.3^{\circ} \mathrm{C}\right)$ and acetonitrile $\left(81.3{ }^{\circ} \mathrm{C}\right)$ are not significantly different, AN is difficult to separate completely using a common distillation operation. Therefore, an extractive distillation process using water as an extractant is conducted in the recovery column to increase the relative volatility of both substances. Separated acetonitrile is transported to an acetonitrile recovery plant and purified, and unrecovered acetonitrile is incinerated in the waste gas incinerator. Water generated from the reaction is recycled as an absorbent for the absorber and a solvent for the recovery column, and surplus water is discharged from the bottom of the recovery column as wastewater that is treated and detoxified in an activated sludge facility before being discharged.

Crude AN containing hydrogen cyanide, from which acetonitrile was separated in the recovery column, is then sent to the heads column where hydrogen cyanide, low boiling point substances, and water are separated. Separated hydrogen cyanide is then sent to a hydrogen cyanide recovery plant or is incinerated in the waste gas incinerator if not recovered. Lastly, high boiling point substances are separated in the product column to obtain AN.

In addition, although not shown in Fig. 1, there is a wastewater treatment process, a waste gas treatment process, and a tank process. In the AN production process, the reactor, quench column, absorber, recovery column, heads column and product column are unique components and are the main equipment used.

Studies related to AN recovery and purification processes have focused on rationalization and improvement of processes from the perspective of reducing manufacturing cost. For example, Pujado et al. (1977) studied improvement of AN recovery/purification processes and Gu et al. (1991) studied the use of xylene instead of water during extraction to separate AN and acetonitrile. Additionally, AN plants also generate large quantities of wastewater and waste gas; therefore, there have also been studies from a waste reduction perspective. Hopper et al. (1993) and Sanghavi (1998) studied waste reduction and Shelly (1995) studied catalytic oxidation treatment of waste gases.

Many previous studies have reported on the AN process' environmental and health risks. (USEPA, 1983; WHO, 1983; TERA, 1997; USEPA, 1998; IARC, 1999). The following studies reported on fire and explosion in AN production processes. Al-Sharrah et al. (2007) proposed a safety risk index to estimate the maximum number of people affected if an accident occurred that caused the release of a plant's entire inventory of a chemical. For the risk analysis, First (2010) presented a simplified chemical process risk analysis method that is effective at providing a semi-quantitative measure of consequence, and mentioned that this method minimizes overall time required for scenario development and re-validation relative to HAZOP. Zhao et al. (2009) developed a new learning HAZOP expert system based on integrating case-based reasoning and ontology to improve HAZOP expert system learning. They used an example of the AN production process with an AN startup furnace ignition failure. Shah et al., 2005 presented a new method using an automated software tool in which a hierarchical approach reveals the degree of non-ideality of chemical processes with regard to safety, health, and environment aspects at different process layers. They provided an example of acrylic fiber 
production, in which they showed the safety assessment of an AN tank. As studies on reaction risks, Cozzani et al. (1998) studied unwanted reactions caused by accidental contact of reactive substances and Miyake et al. (2005) proposed an evaluation flow of hazards of mixing organic peroxides with other chemicals such as AN. As described above, there have been many risk assessment studies, but there have not been enough studies on the cost-effectiveness of risk reduction for AN plants, thus there is room for improvement.

\section{Consideration for Physical Risk Assessment}

\subsection{Risk assessment targets}

After quantitatively deriving each AN plant unit's risk level, it is crucial to grasp relative risk levels between all units and those with high risk levels. In this study, we conducted a safety assessment of an AN plant using Dow's Fire \& Explosion Index Hazard Classification Guide (AIChE, 1994) (hereinafter referred to as F\&EI).

This method classifies the plant into different units based on characteristics and/or physical layout. Characteristic classification is a concept similar to unit operation used in chemical engineering processes in which ordinary plants are divided around the main equipment. In this study, the goal was to find hazards of the process. Therefore, an F\&EI unit was not selected as a section, but rather each main equipment component constituted a section. Because evaluation focused on processes, tanks that did not involve chemical engineering unit operations were not evaluated. We employed the following assumptions:

a) AN plant operation consists of reaction, recovery, and purification processes. Because these definitions are somewhat coarse in this case, each main piece of equipment composing an AN plant was taken as an F\&EI unit. Those units are the reactor, the quench column, the absorber, the recovery column, the heads column, and the product column.

b) Plant size (i.e. production capacity) should be cost competitive; therefore, we targeted large plants worldwide $(200 \mathrm{kt} / \mathrm{y})$.

c) The plant follows the world standard and has two reactors, two quench columns, one absorber, one recovery column, one heads column, and one product column.

d) Material coefficients (i.e., material factors) were determined by weighted averaging from the mixture composition. The mass of materials in each piece of equipment was determined by calculating retention amounts and equipment size.

The method for calculating the F\&EI value is described using a reactor as an example. The F\&EI value is calculated using two components, Material Factor (MF) and Process Unit Hazards Factor (F3), which consists of General Process Hazards (F1) and Special Process Hazards (F2). The F\&EI value is determined by Eqs. (3.1) and (3.2) (AIChE, 1994): 


$$
\begin{aligned}
& F \& E I=M F \times F 3 \\
& F 3=F 1 \times F 2
\end{aligned}
$$

MF is the rate of potential energy release from chemicals/materials, indicated by a value of 1 to 40 , and can be determined from chemical/materials reactivity and flammability. The MF for main substances is given in the table of guidelines (AIChE, 1994). The MF value in the reactor was calculated to be 36 .

F1 determines a potential incident's magnitude and covers exothermic chemical reactions, endothermic processes, material handling and transfer, enclosed or indoor process units, access and drainage and spill control. The score standard is described in the AIChE (1994) guidelines. The reactor corresponds to an exothermic reaction and $\mathrm{F} 1$ was calculated to be 1.50 .

F2 determines a potential incident's probability and consists of 12 items (toxic material, sub-atmospheric pressure, operation in or near flammable range, dust explosion, relief pressure, low temperature, quantity of flammable/unstable material, corrosion and erosion, leakage-joints and packing, use of fire equipment, hot oil heat exchange system, and rotating equipment). From the score given in the AIChE (1994) guidelines. F2 in the reactor was calculated to be 3.78 .

Therefore, from Eq. (3.2), F3 = $1.50 \times 3.78=5.67$, and from Eq. (3.1), F\&EI $=36 \times 5.67=204$.

The degree of hazard based on F \& EI values is classified as shown in Table 2 (AIChE, 1994) and the resulting values shown in Table 3 clearly indicate that all degrees of hazard of AN plant units were classified as "Heavy" and "Severe." The reactor has a maximum F\&EI value of 204, whereas the product column had the next highest value at 185 . Hereafter, we focus on the reactor, which has high risks associated with fires and explosions as this study's subject.

Table 2 Fire \& Explosion Index (F\&EI) risk rank.

\begin{tabular}{cc}
\hline F\&EI Range & Degree of Hazards \\
\hline $1-60$ & Light \\
\hline $61-96$ & Moderate \\
\hline $97-27$ & Intermediate \\
\hline $128-158$ & Heavy \\
\hline$>159$ & Severe
\end{tabular}

F \& EI = Fire and Explosion Index 
Table 3 Fire \& Explosion Index (F\&EI) evaluation result.

\begin{tabular}{lc}
\hline \multicolumn{1}{c}{ Unit } & F\&EI \\
\hline Reactor & 204 \\
\hline Quench Column & 134 \\
\hline Absorber & 132 \\
\hline Recovery Column & 150 \\
\hline Heads Column & 136 \\
\hline Product Column & 185 \\
\hline
\end{tabular}

F \& EI = Fire and Explosion Index

\subsection{Risk assessment method}

To enhance risk identification completeness in this study, we conducted risk identification using the following considerations:

a) Partial oxidation reaction process characteristics obtained from actual plant operation.

b) AN fluidized bed reactor characteristics obtained from actual plant operation.

c) Natural disasters.

d) Cyber-attacks and terrorism.

By using HAZOP and/or FMEA, risk identification completeness for a) and b) can be improved.

Natural disasters have rarely been considered in past risk assessments; however, natural disasters can trigger industrial accidents at chemical plants. In recent years, industrial accidents caused by natural disasters have attracted attention and are referred to hereinafter as Natech. For example, two earthquakes in northwest Turkey caused heavy damage to many industrial facilities (Korkmaz et al., 2011), and hurricanes and earthquakes have caused hazardous material releases from chemical plants (Cruz et al., 2009; Krausmann et al., 2010). One such example is Hurricane Harvey, which hit the state of Texas in the United States of America in 2017. The hurricane seriously damaged public infrastructure and plant equipment, forcing many of the chemical plants in the area into a force majeure declaration and caused them to shut down for several months. In Japan, damages from typhoon winds and flooding and due to earthquakes or tsunami cannot be ignored. Regarding Japanese chemical plants, it has been revealed that correspondence behaviors at the time of the 2011 Great East Japan Earthquake (also known as the Tohoku Earthquake) were not necessarily sufficient with respect to countermeasures after the earthquake (Yu et al., 2017). Research on Natech is progressing with case studies, the advancement of risk assessment methods and the organization of matters necessary for management. Although understanding of Natech risk has deepened, there are several features compared to fire/explosion risk, etc. that need further study, and proposals for better management methods are expected in the future. 
To concretely implement physical risk reduction measures, it is necessary to break down scenarios leading to accidents or disasters. We selected FTA as the analysis method to obtain the following results by risk assessment.

$\checkmark$ Clarify serious event scenarios

$\checkmark \quad$ Extract and clarify fatal events in the system and lead to system improvement

$\checkmark \quad$ Evaluate the importance of each basic event

$\checkmark$ Compare the occurrence probability of a serious event (top event) from those of basic events

To enhance risk identification completeness in the FTA, we incorporated all reasonably foreseeable events related to matters a) through d) in Section 3.2. We will thus conduct a cost-benefit analysis based on FTA results.

\subsection{FTA events}

We examined events related to physical risks in the reaction section based on the perspectives described in Section 3.2. As a result, top events were derived from events caused by "characteristics of partial oxidation reaction process obtained from actual plant operation." Top events with a high priority in handling due to serious accidents were identified as "fire/explosion outside the reactor," "fire/explosion inside the reactor," and "reactor destruction" (Fig. 2). It can be said that these are accidents that would be troublesome if they were to happen.
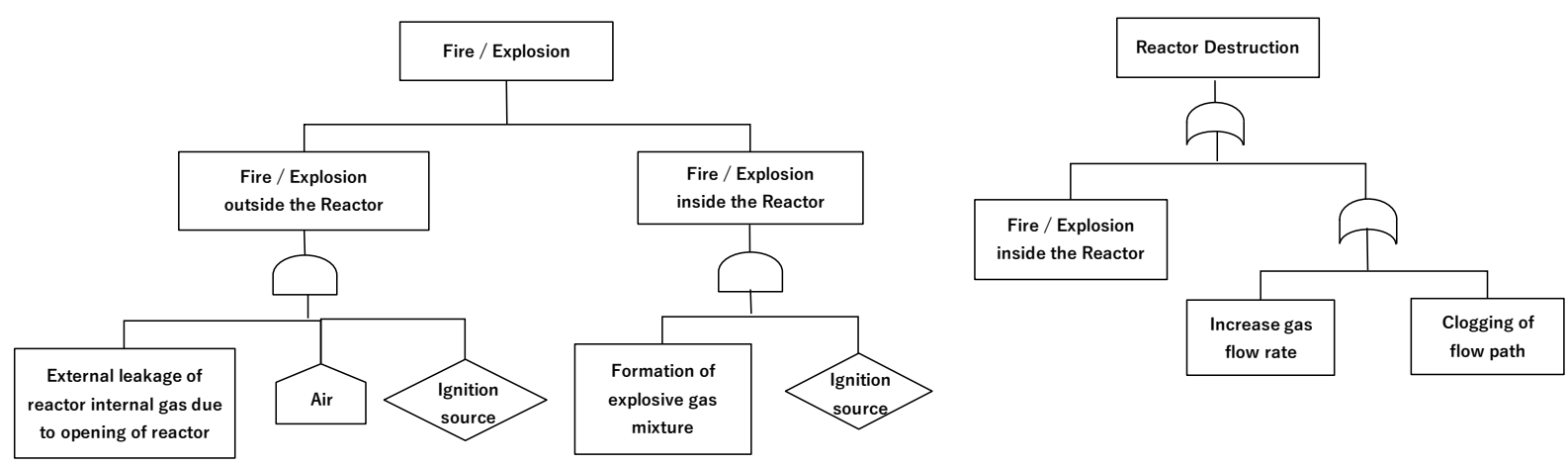

Fig. 2 Top events. Events related to physical risk in an acrylonitrile plant reaction section. The top events identified are fire/explosion outside the reactor, fire/explosion inside the reactor, and reactor destruction.

We obtained intermediate events constructing accident scenarios and basic events from "characteristics of equipment including fluidized bed reactors." In other words, these events were single failures of equipment and parts, failures caused by excessive stress on equipment and parts, and failures due to operation/handling errors.

As for the events that could be caused by natural disasters and cyber-attacks or terrorism, loss of utility, loss of operation control, equipment destruction, etc. were considered. These were events that affected all events and were defined as common failures.

The above descriptions are summarized in Fig. 3. 
Common failures are often related to top events as well as many intermediate/basic events, so putting common failures in an FTA makes the FT diagram complicated. Consequently, common failures were separated from FTA because targets for reducing risks that affect AN reaction process physical hazards targeted in this study are ambiguous.
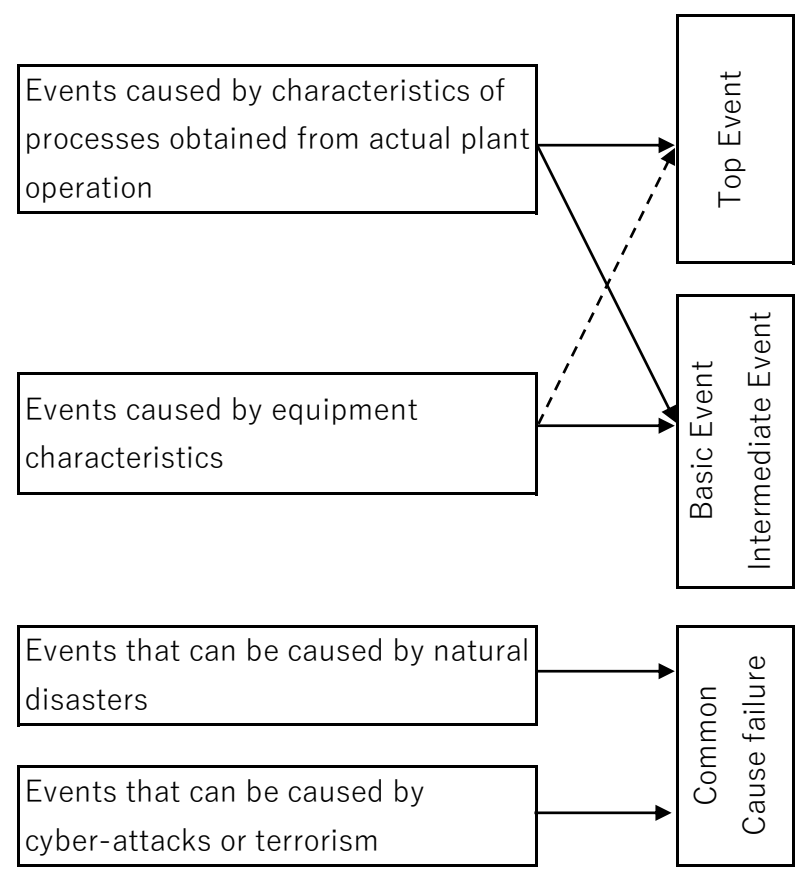

Fig. 3 Identified events. Top events are derived from events caused by characteristics of partial oxidation reaction process obtained from actual plant operation. We obtained intermediate events for constructing accident scenarios and information to be considered as basic events from characteristics of equipment including fluidized bed reactors. Events that could be caused by natural disasters, cyber-attacks, or terrorism are positioned as causes of common failure, and thus would be related to all top events.

\subsection{Accident case in the reaction process}

To verify the identified risk, we collected 102 cases of AN plant reaction process accidents from AN manufacturing companies around the world and classified and consolidated AN fluidized bed reactor accident cases worldwide. Table 4 shows the aggregated results obtained by this work.

Table 4 refers to accident cases, but we found that abnormalities can be classified as either "accidents/disasters" or "incidents." Accidents and disasters include events such as explosions, fires and pressure abnormalities. Notification of accidents or disasters is given both inside and outside the company, with public reports being made depending on the scale of the accident/disaster. Incidents include events such as reaction temperature abnormalities, hot spots, leakage, and cyclone abnormalities. These events were determined by post-inspection and treated using unsteady operation, though in some cases urgent action was taken and incidents were calmed down before an accident/disaster occurred. 
Table 4 Examples of accidents in acrylonitrile fluidized bed reactors.

\begin{tabular}{|c|c|c|c|c|c|}
\hline Type of & Abnormal & Number & & Contents & Cause \\
\hline event & Form & & & & \\
\hline $\begin{array}{l}\text { Accident/ } \\
\text { Disaster }\end{array}$ & Explosion & 14 & $\mathrm{~S} / \mathrm{D}$ & $\begin{array}{l}\text { Explosion occurred in the reactor, quench } \\
\text { column, or absorber when } \mathrm{C} 3 \mathrm{H} 6 \text { and } \mathrm{NH} 3 \text { were } \\
\text { stopped at the same time. }\end{array}$ & $\begin{array}{l}\text { Under air shutoff delay and/or air purge } \\
\text { continuation, the explosive mixture gas was } \\
\text { formed. }\end{array}$ \\
\hline $\begin{array}{l}\text { Accident/ } \\
\text { Disaster }\end{array}$ & Fire & 1 & $\mathrm{~S} / \mathrm{U}$ & $\begin{array}{l}\text { During S/U after emergency stop, gas blew out of } \\
\text { the bottom of the reactor and ignited. }\end{array}$ & $\begin{array}{l}\text { When the emptying stopped, Mo pieces dropped } \\
\text { and accumulated, inhibiting catalyst fluidization, } \\
\text { and abnormal high temperature was formed due } \\
\text { to insufficient heat removal. }\end{array}$ \\
\hline Incident & $\begin{array}{l}\text { Reaction } \\
\text { Temperature }\end{array}$ & 3 & $\mathrm{~S} / \mathrm{U}$ & $\begin{array}{l}\text { The temperature of the upper part of the reactor } \\
\text { sharply increased at the stage of temperature rise } \\
\text { or temperature decrease due to } \mathrm{NH} 3 \text { combustion. }\end{array}$ & $\begin{array}{l}\text { Dense phase temperature dropped due to } \\
\text { excessive use of cooling coils and a large } \\
\text { amount of } \mathrm{NH} 3 \text { burned in a dilute phase. }\end{array}$ \\
\hline Incident & $\begin{array}{l}\text { Reaction } \\
\text { Temperature } \\
\text { Low }\end{array}$ & 2 & $\begin{array}{l}\text { Nor. } \\
\text { Ope. }\end{array}$ & $\begin{array}{l}\text { Mist was entrained from the raw material gas } \\
\text { vaporizer and the reactor temperature sharply } \\
\text { dropped. This led to increased unreacted and } \\
\text { induced temperature runaway in the waste gas } \\
\text { incinerator. }\end{array}$ & $\begin{array}{l}\text { The level meter of the raw material gas vaporizer } \\
\text { failed. }\end{array}$ \\
\hline $\begin{array}{l}\text { Accident/ } \\
\text { Disaster }\end{array}$ & $\begin{array}{l}\text { Pressure } \\
\text { High }\end{array}$ & 15 & $\begin{array}{l}\text { Nor. } \\
\text { Ope. }\end{array}$ & $\begin{array}{l}\text { The flow of reaction gas was inhibited and reactor } \\
\text { pressure rose. }\end{array}$ & $\begin{array}{l}\text { Clogging of reactor effluent cooler, clogging of } \\
\text { quench column packed bed, closing of quench } \\
\text { column outlet CV }\end{array}$ \\
\hline \multirow[b]{2}{*}{ Incident } & \multirow[b]{2}{*}{ Hot spot } & 3 & $\mathrm{~S} / \mathrm{U}$ & $\begin{array}{l}\mathrm{NH} 3 \text { abnormally burned and damaged on the } \\
\text { upper tube sheet of the reactor effluent cooler. }\end{array}$ & $\begin{array}{l}\text { The catalyst accumulated on the tube sheet and } \\
\text { the temperature rose due to } \mathrm{NH} 3 \text { combustion. }\end{array}$ \\
\hline & & 11 & $\begin{array}{l}\text { Nor. } \\
\text { Ope. }\end{array}$ & $\begin{array}{l}\text { Sparger nozzles, flanges, and support lugs were } \\
\text { melted. }\end{array}$ & $\begin{array}{l}\text { Because internal cleaning was not done when the } \\
\text { reactor was stopped, Mo pieces accumulated and } \\
\text { deteriorated catalyst fluidization. Inadequate } \\
\text { distance and structure between sparger and air } \\
\text { distributor. }\end{array}$ \\
\hline \multirow[t]{2}{*}{ Incident } & \multirow[t]{2}{*}{ Leakage } & 9 & $\begin{array}{l}\text { Nor. } \\
\text { Ope. }\end{array}$ & $\begin{array}{l}\text { The cooling coil was broken, causing catalyst } \\
\text { cracking and catalyst scattering. }\end{array}$ & $\begin{array}{l}\text { Cracking occurred due to stress concentration in } \\
\text { the welded parts of the cooling coils and BFW } \\
\text { blew out. }\end{array}$ \\
\hline & & 13 & $\begin{array}{l}\text { Nor. } \\
\text { Ope. }\end{array}$ & $\begin{array}{l}\text { Sparger was broken, unreacted raw material } \\
\text { increased, and waste gas incinerator temperature } \\
\text { increased. }\end{array}$ & $\begin{array}{l}\text { Breakage of sparger due to material degradation } \\
\text { Flange fastening problem }\end{array}$ \\
\hline \multirow[t]{2}{*}{ Incident } & Cyclones & 10 & any & $\begin{array}{l}\text { Cyclone was blocked by catalyst and a large } \\
\text { amount of catalyst scattered. }\end{array}$ & $\begin{array}{l}\text { Dip-leg obstruction } \\
\text { Trickle valves malfunction }\end{array}$ \\
\hline & abnormality & & Nor. & $\begin{array}{l}\text { A hole opened in the cyclone and a large amount } \\
\text { of catalyst scattered. }\end{array}$ & Dust balls were broken by erosion. \\
\hline Incident & $\begin{array}{l}\text { External } \\
\text { Factor }\end{array}$ & 21 & $\begin{array}{l}\text { Nor. } \\
\text { Ope. }\end{array}$ & \multicolumn{2}{|c|}{$\begin{array}{l}\text { Blackout, machine/instrumentation/electrical equipment failure, emergency stop due to natural } \\
\text { disaster }\end{array}$} \\
\hline
\end{tabular}

S/U: Start up; S/D: Shut down; Nor.Ope.: Normal operation

Sparger : Disperser (nozzles that discharge raw material gas)

Air distributor : Plate with nozzles to discharge air

Cyclones: Apparatus for recovering catalyst from gas flow

Cooling coils : Cooling device for removing heat of reaction

BFW: Boiler feed water

CV: Control valve 
We defined 30 cases - 14 explosions, one fire, and 15 pressure abnormalities - as accidents/disasters, accounting for $29 \%$ of all cases, and the remaining $71 \%$ were defined as incidents. Among these, 51 cases of high temperature, low temperature, hotspots, leakage, and cyclone abnormalities accounted for $50 \%$ of the total. The remaining 21 incidents $(21 \%)$ were due to blackouts, machine issues (machine or instrumentation failures), and natural disasters (typhoons). Although these incidents did not lead to accidents or disasters, they caused unintended emergency reactor shutdowns.

Table 4 shows that accidents/disasters have occurred not only during unsteady operation such as plant startup and shutdown, but also during steady operation. Thus, it is shown that measures must be taken regardless of operating conditions.

From the cases described in Table 4, it is possible to understand the types of physical risk that occur during the AN reaction process (Table 5).

Table 5 Types of physical risks in acrylonitrile fluidized bed reactors.

\begin{tabular}{|c|c|}
\hline Fire & Gas leakage leads to jet fire \\
\hline \multirow{2}{*}{ Explosion } & Gas explosion \\
\hline & Explosion due to pressure rise (abrupt pressure change, expansion of liquid) \\
\hline \multirow{2}{*}{ Leakage } & Leakage of raw material gas from gas supply system \\
\hline & Leakage of reaction gas from reactor (leads to fire/explosion.) \\
\hline \multirow[b]{2}{*}{ Destruction } & Destruction due to pressure rise due to explosion inside the reactor \\
\hline & $\begin{array}{l}\text { Due to the reactor internal pressure being increased due to reactor outlet closing and gas } \\
\text { supply continuation }\end{array}$ \\
\hline
\end{tabular}

Because incidents can lead to accidents/disasters, it is possible to connect accidents/disasters with related incidents. Likewise, relevant incidents are also connected with other incidents. For example, in the pressure abnormality case, measures were taken before the reactor was destroyed, but it was not distinguished from a breakdown. Therefore, the pressure abnormality case was not classified as an incident, but rather was treated as an accident/disaster.

Fig. 4 was created based on the above idea. Explosions and fires were mainly classified in the block with chemical reactions, wheras destruction was mainly classified in the block with physical phenomenon.

As shown in Fig. 4, accidents and disasters are consistent with top events identified using the method described in Sections 3.2 and 3.3, suggesting the validity of those methods. Furthermore, events identified using the method described in Section 3.2 and 3.3 covers accident/disaster cases. In other words, it was not necessary to supplement the identified events with accident/disaster cases.

If it is possible to detect the occurrence of incidents that can lead to explosion, fire, or destruction, thereby suppressing their expansion, it can be said that accident/disaster risks can be reduced. Thus, it is important to 
systematically extract incidents leading to accidents or disasters from the perspective of preventing them and taking countermeasures.

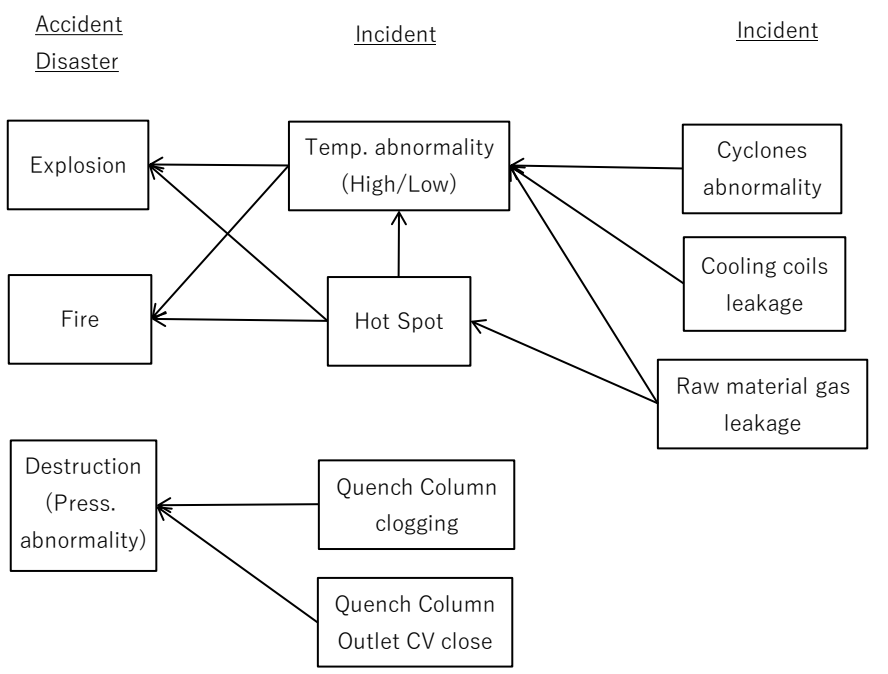

Fig. 4 System diagram of the accidents. Incidents can be accidents or disasters or can cause them, and it is possible to connect accidents and disasters with related incidents. Likewise, relevant incidents are also frequently connected with other incidents. Explosion and fire are mainly classified in a block with chemical reactions and destruction is mainly classified in a block with physical phenomena.

\subsection{Evaluation of severity of accidents}

The Center for Chemical Process Safety (CCPS) proposed an index, known as the CCPS Process Safety Metrics, for determining the degree of event severity (CCPS Process Safety Leading and Lagging Metrics, 2011). This index is a common metric for conducting self-evaluations for petrochemical and fine chemical industries. The CCPS index aims at preventing process accidents and disasters and quantitatively evaluates four levels of four items: human health, fire/explosion, potential impact of leakage, and environmental impact. The final score is the total of points for each of these items and shows accident severity. The Japan Petrochemical Industry Association added a minor accident level to the CCPS index and set each item to five levels as shown in Table 6. Using the degree of severity from this index as a single indicator allows us to directly compare the sizes of each accident. 
Table 6 Center for Chemical Process Safety (CCPS) points.

\begin{tabular}{|c|c|c|c|c|}
\hline $\begin{array}{l}\text { Severity } \\
\text { Level } \\
\text { (points) }\end{array}$ & $\begin{array}{l}\text { Human } \\
\text { Health }\end{array}$ & $\begin{array}{c}\text { Fire or } \\
\text { Explosion }\end{array}$ & $\begin{array}{c}\text { Potential } \\
\text { Chemical } \\
\text { Impact }\end{array}$ & $\begin{array}{l}\text { Community / } \\
\text { Environment } \\
\text { Impact }\end{array}$ \\
\hline $1(27)$ & Multiple fatalities & $\begin{array}{l}\text { Direct Cost } \\
>1 \text { Byen }\end{array}$ & $\begin{array}{l}\text { Chemical release with } \\
\text { potential for significant on-site } \\
\text { or off-site injuries or fatalities }\end{array}$ & $\begin{array}{c}\text { National media coverage over multiple days } \\
\text { OR Environmental remediation required and } \\
\text { cost in excess of } 250 \text { Myen. Federal } \\
\text { government investigation and oversight of } \\
\text { process. OR other significant community } \\
\text { impact }\end{array}$ \\
\hline $2(9)$ & 1 fatality & $\begin{array}{l}100 \text { Myen- } \\
1 \text { Byen }\end{array}$ & $\begin{array}{l}\text { Chemical release with } \\
\text { potential for injury off site }\end{array}$ & $\begin{array}{l}\text { Shelter-in-place or community Evacuation } \\
\text { OR Environmental remediation required and } \\
\text { cost in between 100Myen-250Myen. State } \\
\text { government investigation and oversight of } \\
\text { process. OR Regional media coverage or } \\
\text { brief national media coverage. }\end{array}$ \\
\hline $3(3)$ & Lost work accident & $\begin{array}{l}10 \text { Myen-- } \\
100 \text { Myen }\end{array}$ & $\begin{array}{l}\text { Chemical release outside } \\
\text { of containment but retained on } \\
\text { company property }\end{array}$ & $\begin{array}{l}\text { Minor off-site impact with precautionary } \\
\text { shelter-in-place OR Environmental } \\
\text { remediation required with cost less than } \\
\text { 100Myen. No other regulatory oversight } \\
\text { required. OR Local media coverage }\end{array}$ \\
\hline $4(1)$ & First aid & $\begin{array}{l}2.5 \text { Myen- } \\
10 \text { Myen }\end{array}$ & $\begin{array}{l}\text { Chemical released within } \\
\text { secondary containment or } \\
\text { contained within the unit }\end{array}$ & $\begin{array}{l}\text { Short-term remediation to address acute } \\
\text { environmental impact. } \\
\text { No long term cost or company oversight. } \\
\text { Examples would include spill cleanup, soil } \\
\text { and vegetation removal. }\end{array}$ \\
\hline $5(0.3)$ & $\begin{array}{l}\text { Does not meet or } \\
\text { exceed Level } 4 \\
\text { threshold }\end{array}$ & $<2.5$ Myen & $\begin{array}{l}\text { Does not meet or exceed Level } \\
4 \text { threshold }\end{array}$ & Does not meet or exceed Level 4 threshold \\
\hline
\end{tabular}

Fig. 5 shows the relationship between total loss amounts and corresponding CCPS scores of accident cases for AN fluidized-bed reactors shown in Table 4. As seen in Fig. 5, the coefficient of determination is low $\left(\mathrm{R}^{2}=0.43\right)$, indicating that the CCPS index cannot estimate damage amounts incurred by a company and society. This is probably because the CCPS evaluation index only covers direct costs. To meet the needs of company with accountability to stakeholders, it is desirable to employ an evaluation index that can express substantial damage the company experiences. 


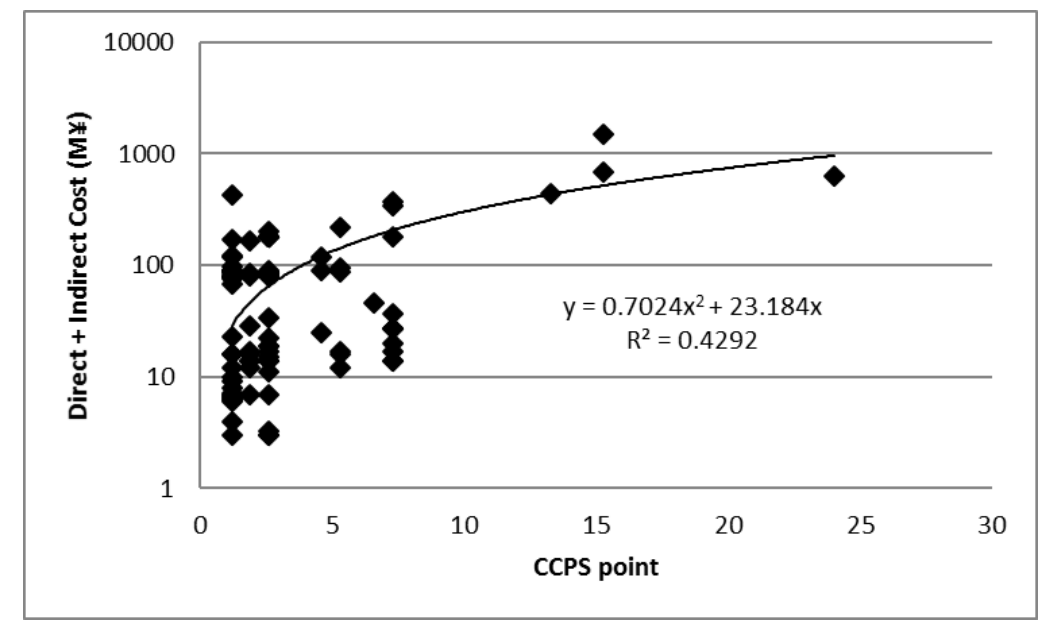

Fig. 5 Relationship between CCPS points and loss amounts. This figure shows the relationship between CCPS points and total loss amounts for the AN fluidized bed reactor accident case shown in Table 4.

Direct costs are expenses such as repair, exchange, cleaning, disposal, environmental restoration, and emergency response. Generally, direct costs do not include lost opportunity, business interruption, loss of raw materials and products, lost profits due to equipment shutdown, costs of procuring and operating temporary equipment, or costs of procuring alternative products to meet customer requests. These expenses are thus known as indirect costs. However, when expressing damage incurred by a company, the weight of indirect costs in the total loss amount cannot be ignored; therefore, it is crucial to also account for indirect costs. Several items in this study are indirect costs; however, we solely adopted opportunity loss due to the size of its effect on indirect cost and to simplify evaluation. That is, to measure the degree of severity, we proposed a revised CCPS (hereinafter referred to as RCCPS) evaluation index that adds opportunity loss to the conventional CCPS evaluation index (Table 7). We set opportunity loss severity to the same level as existing evaluation items. For this purpose, we first set length of stoppage to roughly the same level by referring to the explanation given for each level described under "Community/Environment Impact" in the conventional CCPS evaluation index. Next, we confirmed that there was no significant difference in the amount of opportunity loss calculated from length of stoppage, loss production volume and marginal profit compared with existing items. Specifically, we set the AN plant production amount to the world standard size of $200 \mathrm{kt} / \mathrm{y}(600 \mathrm{t} / \mathrm{D})$ and set the marginal profit to $30,000 ¥ /$ t. We set length of stoppage levels as follows: 2 months or more was set to level 1, 1 week-2 months was set to level 2, 1 day-1 week was set to level 3, and 3 hours-1 day was set to level 4. Additionally, we corrected historical loss amount data considering current price levels and used an exchange rate of $100 \mathrm{JPY}$ $(¥)=1$ US\$. 
Table 7 Revised Center for Chemical Process Safety (CCPS) points.

\begin{tabular}{|c|c|c|c|c|c|}
\hline $\begin{array}{l}\text { Severity } \\
\text { Level } \\
\text { (points) }\end{array}$ & $\begin{array}{l}\text { Human } \\
\text { Health }\end{array}$ & $\begin{array}{c}\text { Fire or } \\
\text { Explosion }\end{array}$ & $\begin{array}{l}\text { Potential } \\
\text { Chemical } \\
\text { Impact }\end{array}$ & $\begin{array}{c}\text { Community / } \\
\text { Environment } \\
\text { Impact }\end{array}$ & $\begin{array}{l}\text { Opportunity } \\
\text { Loss }\end{array}$ \\
\hline $1(27)$ & Multiple fatalities & $\begin{array}{l}\text { Direct Cost } \\
>1 \text { Byen }\end{array}$ & $\begin{array}{l}\text { Chemical release with } \\
\text { potential for significant on- } \\
\text { site or off-site injuries or } \\
\text { fatalities }\end{array}$ & $\begin{array}{l}\text { National media coverage over multiple } \\
\text { days OR Environmental remediation } \\
\text { required and cost in excess of } 250 \mathrm{Myen} \text {. } \\
\text { Federal government investigation and } \\
\text { oversight of process. OR other } \\
\text { significant community impact }\end{array}$ & $>1$ Byen \\
\hline $2(9)$ & 1 fatality & $\begin{array}{l}100 \text { Myen- } \\
1 \text { Byen }\end{array}$ & $\begin{array}{l}\text { Chemical release with } \\
\text { potential for injury off site }\end{array}$ & $\begin{array}{l}\text { Shelter-in-place or community } \\
\text { Evacuation OR Environmental } \\
\text { remediation required and cost in } \\
\text { between 100Myen-250Myen. State } \\
\text { government investigation and oversight } \\
\text { of process. OR Regional media coverage } \\
\text { or brief national media coverage. }\end{array}$ & $\begin{array}{l}100 \text { Myen- } \\
1 \text { Byen }\end{array}$ \\
\hline $3(3)$ & Lost work accident & $\begin{array}{l}10 \text { Myen- } \\
100 \text { Myen }\end{array}$ & $\begin{array}{l}\text { Chemical release outside } \\
\text { of containment but } \\
\text { retained on company } \\
\text { property }\end{array}$ & $\begin{array}{l}\text { Minor off-site impact with precautionary } \\
\text { shelter-in-place OR Environmental } \\
\text { remediation required with cost less than } \\
\text { 100Myen. No other regulatory oversight } \\
\text { required. OR Local media coverage }\end{array}$ & $\begin{array}{l}10 \text { Myen- } \\
100 \text { Myen }\end{array}$ \\
\hline $4(1)$ & First aid & $\begin{array}{l}\text { 2.5 Myen-- } \\
\text { 10 Myen }\end{array}$ & $\begin{array}{l}\text { Chemical released within } \\
\text { secondary containment or } \\
\text { contained within the unit }\end{array}$ & $\begin{array}{l}\text { Short-term remediation to address acute } \\
\text { environmental impact. } \\
\text { No long term cost or company oversight. } \\
\text { Examples would include spill cleanup, } \\
\text { soil and vegetation removal. }\end{array}$ & $\begin{array}{l}\text { 2.5 Myen- } \\
10 \text { Myen }\end{array}$ \\
\hline $5(0.3)$ & $\begin{array}{l}\text { Does not meet or } \\
\text { exceed Level } 4 \\
\text { threshold }\end{array}$ & $<2.5$ Myen & $\begin{array}{l}\text { Does not meet or exceed } \\
\text { Level } 4 \text { threshold }\end{array}$ & $\begin{array}{l}\text { Does not meet or exceed Level } 4 \\
\text { threshold }\end{array}$ & $<2.5$ Myen \\
\hline
\end{tabular}

100 yen $=1 \$$

Table 4 was rearranged following the RCCPS evaluation index, and thus we drew Fig. 6, which depicts the relationship between total loss amounts and corresponding RCCPS points and indicates a good fit of the model $\left(\mathrm{R}^{2}=0.71\right)$.

The RCCPS evaluation index can use degree of severity as a single indicator and thus compare the scale of accidents. For past accidents scores are 45 or less. In other words, no accident cases exceeded a score of 45 . 


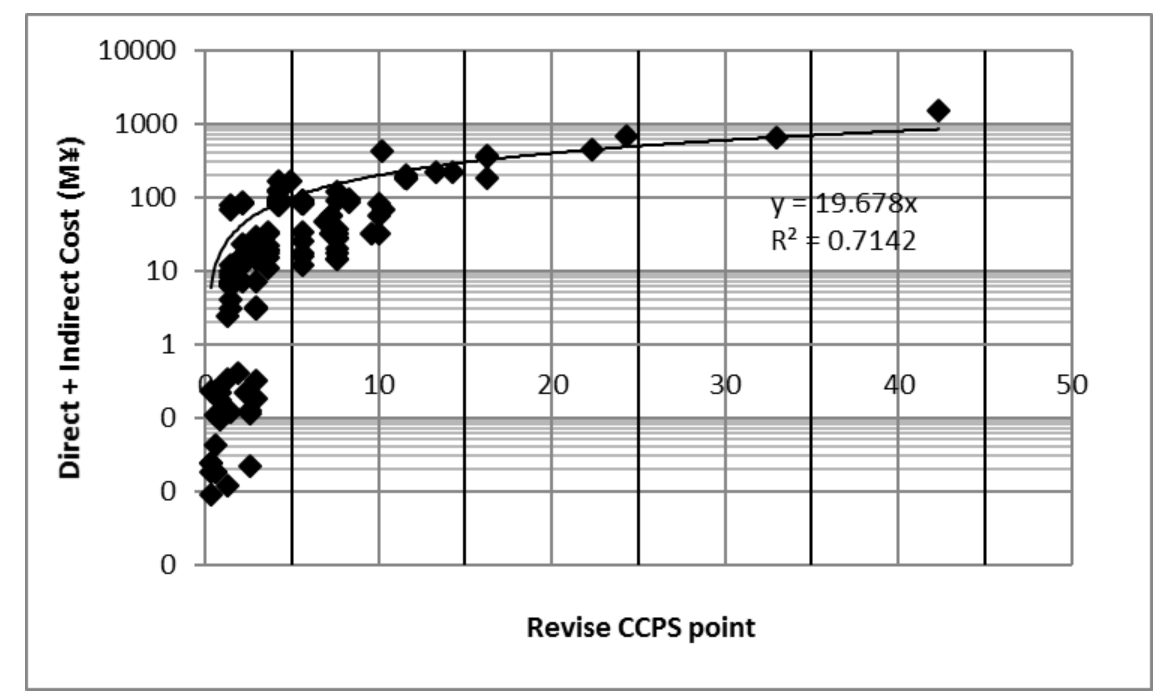

Fig. 6 Relationship between revised CCPS points and loss amounts. This figure shows the relationship between the revised CCPS points and total loss amounts.

\section{Risk Assessment by FTA and Risk Reduction}

\subsection{Severity of top events}

The analysis in the previous section identified three top events, which are addressed with high priority to reduce risk. We expressed the severity for each of these three events using RCCPS scores. Severity level has thresholds for considering human health, fire/explosion, leakage, environmental costs, and opportunity loss. We determined the average severity level to be an intermediate value between the maximum and minimum severity levels. In the absence of an intermediate value, we selected a point based on a judgment of whether there was a shift toward the maximum side or the minimum side due to influence of the occurrence of the target top event. We then calculated the loss amount using the correlation formula shown in Fig. 6. From Fig. 6, RCCPS scores were applied up to 50 to apply the correlation equation. When RCCPS scores were $>50$, it is possible that catastrophic damage to some equipment and significant increases in opportunity loss occurred due to the accident as this would be an accident with an unprecedented score. The loss amount when a RCCPS score is 50 is calculated to be $984 \mathrm{M} ¥$ (about $1000 \mathrm{M} ¥$ ) based on the correlation formula. Therefore, considering the possibility that extrapolating the loss amount seriously affected estimation accuracy, we did not use the correlation equation to calculate the loss amount, and when RCCPS score is $>50$, it was set to $>1000$ M¥ (Fig. 7). 


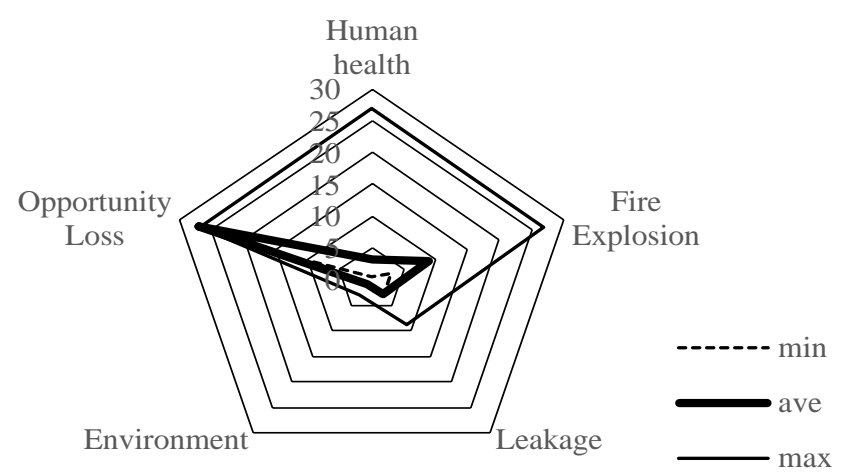

(a) Fire / Explosion outside the Reactor

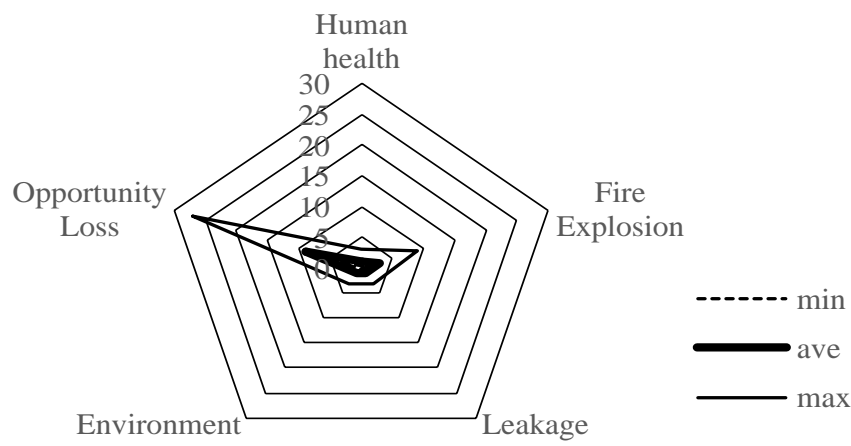

(b) Fire / Explosion inside the Reactor
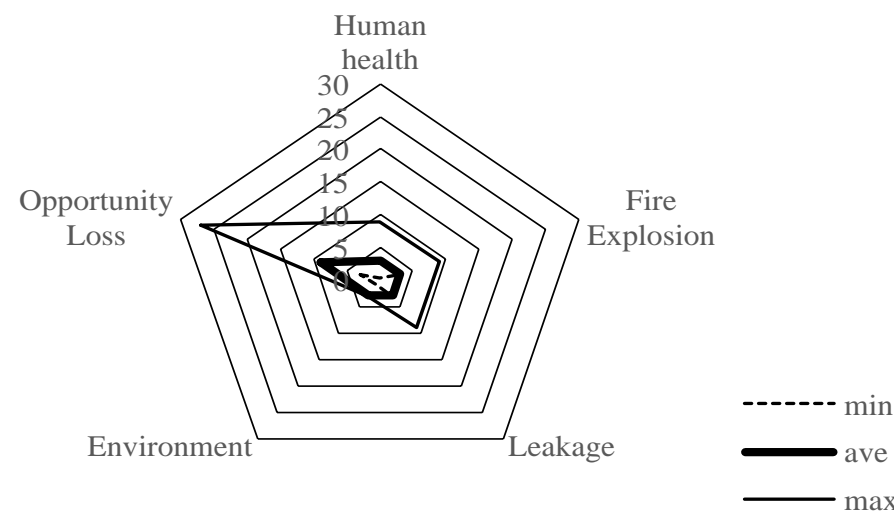

\begin{tabular}{lrr}
\hline & $\begin{array}{c}\text { RCCPS } \\
\text { points }\end{array}$ & \multicolumn{1}{c}{$\begin{array}{c}\text { Loss } \\
\text { (Myen) }\end{array}$} \\
\hline \hline min & 16 & 321 \\
\hline ave & 43 & 846 \\
\hline $\max$ & 93 & $>1000$ \\
\hline
\end{tabular}

\begin{tabular}{lrr}
\hline & $\begin{array}{c}\text { RCCPS } \\
\text { points }\end{array}$ & \multicolumn{1}{c}{$\begin{array}{c}\text { Loss } \\
\text { (Myen) }\end{array}$} \\
\hline \hline min & 4.9 & 96 \\
\hline ave & 15 & 295 \\
\hline $\max$ & 45 & 886
\end{tabular}

\begin{tabular}{lrr}
\hline & $\begin{array}{c}\text { RCCPS } \\
\text { points }\end{array}$ & \multicolumn{1}{c}{$\begin{array}{c}\text { Loss } \\
\text { (Myen) }\end{array}$} \\
\hline \hline $\min$ & 10 & 203 \\
\hline ave & 21 & 413 \\
\hline $\max$ & 57 & $>1000$ \\
\hline
\end{tabular}

(c) Reactor Destruction

Fig. 7 Revised CCPS points and loss amounts for three top events. The severity for three events is expressed using RCCPS points. In the pentagon graphs, the green, red, and blue lines represent the maximum, average, and minimum points, respectively. The loss amounts were calculated using the correlation formula in Fig. 6. 
We found "fire and explosion outside the reactor" to be high, thus we discuss fire and explosion outside the reactor hereafter. We explain creating the FT diagram, estimating the probability of occurrence, identifying portions for risk reduction, and selecting capital investment aimed at risk reduction. For loss amount, we used the average value.

\subsection{FTA and top event occurrence probability}

\section{(1) Creating the FT diagram}

We created an FT diagram (Fig. 8) that used fire/explosion outside the reactor as the top event and considered the intermediate and basic events identified in Sections 3.2 and 3.3.

The FT diagram made the accident scenario clear. From an FT diagram, it is possible to identify incidents that do not lead to major accidents like the top event. Also, when new risk identification is performed and risks are added in the future, it will be possible to improve completeness by adding to this diagram.

\section{(2) Unavailability of system}

If many installed components $(\mathrm{m})$ are present and a long time period $(T)$ elapses, the failure rate $(\lambda)$ can be given using the following equation.

$$
\lambda=\frac{n}{m T}
$$

where $n$ is the number of observed failures of independent components during the operation time $T$.

Here we assume that the proportion of failures over time is proportional to the equipment in operation at that time, and the proportional constant is $\lambda$. In this case, an ordinary differential equation of the following formula holds.

$$
\frac{d N}{d t}=-\lambda N
$$

where $\mathrm{N}$ is the number of pieces of equipment in operation. The number of specimens in the initial state is $N_{0}$ and both sides are divided by $N_{0}$. If $P=N / N_{0}$,

$$
\frac{d P}{d t}=-\lambda P
$$

When $t=0$, as $P=1$,

$$
\mathrm{P}=e^{-\lambda t}
$$

$P$ is known as availability and $1-P$ is unavailability, $F$. That is,

$$
\mathrm{F}=1-e^{-\lambda t}
$$




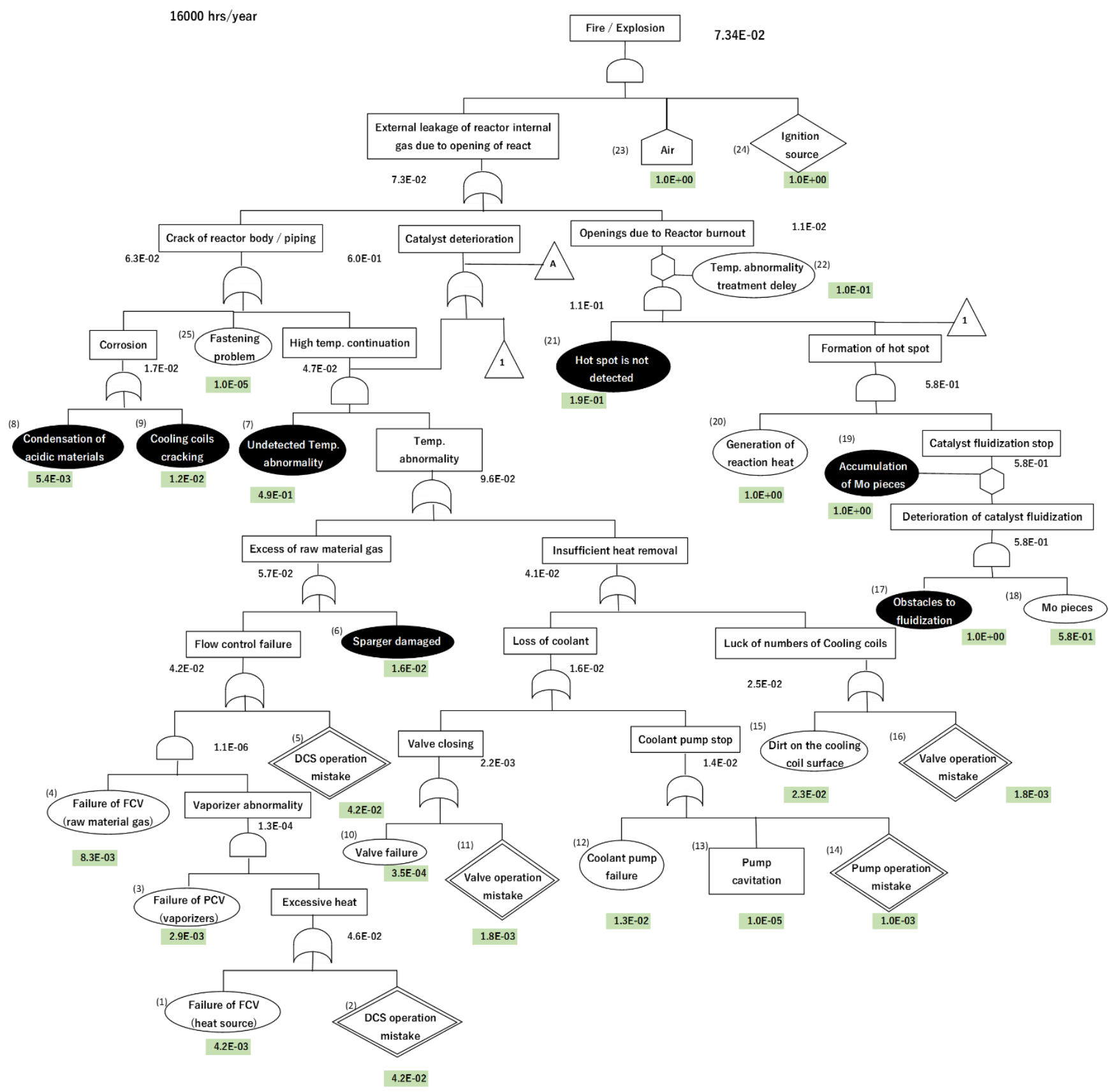

Fig. 8 Fault tree diagram (fire/explosion outside reactor). This is the fault tree diagram for the case of fire/explosion outside reactor. Green hatching indicates the occurrence probability of the basic event. Black hatching indicates events related to the equipment or phenomena of acrylonitrile reaction section.

Generally, in quantitative risk assessment analysis, because $1 \gg \lambda t$ holds, the second term on the right side of Eq. (4.6) can be approximated by the expanded formula.

$$
\mathrm{F}=1-e^{-\lambda t} \approx 1-(1-\lambda t)+\frac{(\lambda t)^{2}}{2 !}-\frac{(\lambda t)^{3}}{3 !}+\cdots \cong \lambda t
$$


That is, unavailability (also known as occurrence probability) can be calculated by multiplying failure rate $\lambda$ and time $t$.

\section{(3) Failure rate}

Failure rate data can be obtained from present databases. Abundant data exists on nuclear power plants, such as the U.S. Nuclear Regulatory Commission, "Component Reliability Data Sheet 2010," USNRC, September 2012, etc. As for chemical plant data, the CCPS Guideline for Process Equipment Reliability Data, with Data Tables (2010) can be used. In contrast, failure rates of specific equipment used in the AN reaction process have not been disclosed until now. In this study, data on the number of failures and total operating time observed from AN plants were obtained, and we used (observed failure number) / (total operating time) ( $1 / \mathrm{h}$ ) as the failure rate. Total operation time exceeds 100,000 hours, which is sufficient to observe the number of failures.

There were some AN reaction process failures that have no history of occurring. Although the occurrence probabilities of some failures are extremely small, they cannot be said to be zero. The total operation time for cases with no records of failure exceeded 100,000 hours, which is considered a satisfactory time period and the probability of failure occurrence is considered to have reached its minimum value. Quoting the allowable value of location-specific individual risk (LSIR) (ISO/TS 16901, 2015), the probability of the failure event occurring was $1.0 \times 10^{-5}$ on the safety side. That is, in this study, the failure occurrence probability was considered the minimum value in the AN plant.

As for unavailability of human error (HE) in the AN reaction process, we selected work described in the literature like that of the AN reaction process, with the assumption that humans always have the same reliability.

Table 8 summarizes failure rates and occurrence probabilities of basic events used to estimate occurrence probabilities of top events by the FT diagram. 
Table 8 Failure rate and occurrence probability. Failure rate unit is 1/hour. Occurrence probability describes the probability of occurring within two years.

\begin{tabular}{|c|c|c|c|c|c|c|}
\hline $\begin{array}{l}\text { Basic } \\
\text { Event } \\
\text { No. }\end{array}$ & Facilities/Operation & Failure & Value & Unit & $\begin{array}{c}\text { Cited } \\
\text { Document }\end{array}$ & Remarks \\
\hline \multirow{7}{*}{ (1) } & \multirow{7}{*}{ Flow control device } & Air operated valve Operation failure & $8.6 \mathrm{E}-08$ & $1 / \mathrm{h}$ & 1) & \multirow{7}{*}{$\begin{array}{l}\text { Consider failure of air operated } \\
\text { valve constituting FCV, flow } \\
\text { measurement unit(RO), and } \\
\text { transmitter respectively. (or) }\end{array}$} \\
\hline & & Air operated valve Accidentally open or close & $1.8 \mathrm{E}-08$ & $1 / \mathrm{h}$ & 1) & \\
\hline & & Air operated valve $\quad$ Clogging & $2.0 \mathrm{E}-08$ & $1 / \mathrm{h}$ & 1) & \\
\hline & & Orifice $\quad$ Internal damage & $1.3 \mathrm{E}-08$ & $1 / \mathrm{h}$ & 1) & \\
\hline & & Orifice Clogging & $2.0 \mathrm{E}-08$ & $1 / \mathrm{h}$ & 1) & \\
\hline & & Flow transmitter Inoperative & $3.1 \mathrm{E}-08$ & $1 / \mathrm{h}$ & 1) & \\
\hline & & Flow transmitter High output/low output & 7.2E-08 & $1 / \mathrm{h}$ & 1) & \\
\hline$(2)$ & Operation by operators & DCS operation mistake & $4.2 \mathrm{E}-02$ & 1/2years & 2) & \\
\hline \multirow{5}{*}{ (3) } & \multirow{5}{*}{ Pressure control device } & Air operated valve Operation failure & $8.6 \mathrm{E}-08$ & $1 / \mathrm{h}$ & 1) & \multirow{5}{*}{$\begin{array}{l}\text { Consider failure of air operated } \\
\text { valve constituting PCV, and } \\
\text { transmitter respectively. (or) }\end{array}$} \\
\hline & & Air operated valve Accidentally open or closed & $1.8 \mathrm{E}-08$ & $1 / \mathrm{h}$ & 1) & \\
\hline & & Air operated valve Clogging & $2.0 \mathrm{E}-08$ & $1 / \mathrm{h}$ & 1) & \\
\hline & & Pressure transmitter Inoperative & 1.3E-08 & $1 / \mathrm{h}$ & 1) & \\
\hline & & Pressure transmitter High output/low output & 4.2E-08 & $1 / \mathrm{h}$ & 1) & \\
\hline (4) & Flow control device & Same as (1) & & $1 / \mathrm{h}$ & 1) & Consider $\mathrm{C} 3 \mathrm{H} 6$ and $\mathrm{NH} 3$ \\
\hline$(5)$ & Operation by operators & DCS operation mistake & $4.2 \mathrm{E}-02$ & $1 / 2$ years & 2) & \\
\hline \multirow[t]{2}{*}{ (6) } & \multirow[t]{2}{*}{ Sparger } & Crack (header) & $6.6 \mathrm{E}-07$ & $1 / \mathrm{h}$ & AN data & \\
\hline & & Crack (nozzles) & $3.4 \mathrm{E}-07$ & $1 / \mathrm{h}$ & AN data & \\
\hline (7) & Reactor & Undetected temperature abnormality & $3.0 \mathrm{E}-05$ & $1 / \mathrm{h}$ & AN data & \\
\hline (8) & Reactor & $\begin{array}{l}\text { Leakage due to corrosion of condensed acidic } \\
\text { material }\end{array}$ & $3.4 \mathrm{E}-07$ & $1 / \mathrm{h}$ & AN data & \\
\hline \multirow{3}{*}{ (9) } & \multirow{3}{*}{ Cooling Coils } & Crack (welding part) & $1.0 \mathrm{E}-05$ & 1/2years & AN data & \multirow[t]{3}{*}{ Consider crack form. (or) } \\
\hline & & Crack (piping) & $1.0 \mathrm{E}-05$ & $1 / 2$ years & AN data & \\
\hline & & Crack (reactor wall weld) & 7.3E-07 & $1 / \mathrm{h}$ & AN data & \\
\hline \multirow[t]{2}{*}{$(10)$} & \multirow{2}{*}{ Manual valves } & Failure of opening or closing & $1.1 \mathrm{E}-08$ & $1 / \mathrm{h}$ & 1) & \\
\hline & & Clogging & $1.1 \mathrm{E}-08$ & $1 / \mathrm{h}$ & 1) & \\
\hline$(11)$ & Operation by operators & Valve operation & $1.8 \mathrm{E}-03$ & 1/2years & 3) & \\
\hline$(12)$ & Electric pumps (water) & Continuous operation failure & $8.1 \mathrm{E}-07$ & $1 / \mathrm{h}$ & 1) & \\
\hline$(13)$ & Pumps & Cavitation & $1.0 \mathrm{E}-05$ & $1 / 2$ years & No data & To be sufficiently low \\
\hline$(14)$ & Operation by operators & Pump operation & $1.0 \mathrm{E}-03$ & 1/2years & 3) & \\
\hline$(15)$ & Cooling coils & $\begin{array}{l}\text { Dirt on the coil surface } \\
\text { (difficulty in recovering heat transfer capability) }\end{array}$ & $1.5 \mathrm{E}-06$ & $1 / \mathrm{h}$ & AN data & \\
\hline$(16)$ & Operation by operators & Valve operation & $1.8 \mathrm{E}-03$ & $1 / 2$ years & 3) & \\
\hline$(17)$ & Reactor & Obstacles to fluidization & $1.0 \mathrm{E}+00$ & $1 / 2$ years & AN data & \\
\hline$(18)$ & Reactor & $\begin{array}{c}\text { Formation of Mo pieces } \\
\text { (size that exacerbates fluidization) }\end{array}$ & $3.6 \mathrm{E}-05$ & $1 / \mathrm{h}$ & AN data & \\
\hline (19) & Reactor & Accumulation of Mo pieces & 9.7E-05 & $1 / \mathrm{h}$ & AN data & \\
\hline$(20)$ & Reactor & Generation of reaction heat & $1.0 \mathrm{E}+00$ & $1 / 2$ years & AN data & \\
\hline$(21)$ & Reactor & Undetected hot spot & $1.2 \mathrm{E}-05$ & $1 / \mathrm{h}$ & AN data & \\
\hline$(22)$ & Operation by operators & $\begin{array}{c}\text { Missed anomalies } \\
\text { (insufficient operation monitoring) }\end{array}$ & $1.0 \mathrm{E}-01$ & 1/2years & No data & $\begin{array}{l}\text { Estimated from actual results to } \\
\text { be less than } 0.05 \text {. Reference } 3 \text { ) } \\
\text { is } 0.15 \text {. Adopt simple average } \\
\text { of both }\end{array}$ \\
\hline$(23)$ & Sustainable gas & & $1.0 \mathrm{E}+00$ & $1 / 2$ years & - & Always present \\
\hline$(24)$ & Ignition source & & $1.0 \mathrm{E}+00$ & $1 / 2$ years & - & Always present \\
\hline (25) & Reactor/piping & Fastening problem & $1.0 \mathrm{E}-05$ & 1/2years & AN data & \\
\hline
\end{tabular}

AN: Acrylonitrile, FCV: Flow control valve, PCV: Pressure control valve, DCS: Distributed control system

1) JANSI-CFR-02, 2016. Estimation of domestic general equipment failure rate considering uncertainty of failure number

(1982-2010, 29 years 56 plants data), June 2016. www.genanshin.jp/archive/failure_rate/data/JANSI-CFR-02.pdf.

2) Gertman, D.I. \& Blackman, H.S., 1994. Human Reliability \& Safety Analysis Data Handbook, John Wiley \& Sons.

3) Williams, J.C., 1999. Human reliability data - the state of the art \& the possibility, in Proc.Reliability '89, Vol.1, UK, June 14/16. 
(4) Probability of top event occurrence

First, each basic event's occurrence probability was calculated as follows and substituted into the green hatched portion of the FT diagram (Fig. 8). We set the operation period to 2 years (16,000 hours), as regular repairs are often performed every 2 years, and calculated each basic event's occurrence probability from Eq. (4.6) using the failure rate $(1 / \mathrm{h})$ listed in Table 8 . In Table 8 , basic events with an occurrence probability of $1 / 2$ years were used as listed.

The "and gate" and "or gate" in the FT diagram (Fig. 8) were calculated as follows:

And gate:

$$
\begin{aligned}
F(t) & =F 1(t) F 2(t) \cdots F n(t) \\
& =\prod_{i=1}^{n} F i(t)
\end{aligned}
$$

Or gate:

$$
\begin{aligned}
F(t) & =1-(1-F 1(t))(1-F 2(t)) \cdots(1-F n(t)) \\
& =1-\prod_{i=1}^{n}[1-F i(t)]
\end{aligned}
$$

where, $F(t)$ is system unavailability and $F i(t)$ is unavailability for event $i$.

Fig. 8 shows that the occurrence probability per two years of top event was calculated as $7.3 \times 10^{-2}$. Because the loss amount is 846 M¥ (average loss amount in Fig. 7), the expected value of the loss amount per two years becomes $62 \mathrm{M} ¥$ based on the product of the occurrence probability and the loss amount.

\subsection{Priority of investment for risk reduction}

It is assumed that general-purpose single equipment (machinery, instrumentation, and electrical equipment commonly used in chemical plants such as pumps, control valves, thermometers, flow meters, and cables) that make up a chemical plant have ordinary reliability for use in chemical plants. Thus, we excluded improving reliability of general-purpose equipment from this study.

Although it can be easily inferred that internal and external factors can change HE, we set it to a constant value in this study. From the perspective of understanding the influence of HE on top event occurrence probability, we doubled each HE's probability of occurrence. The top event's occurrence probability reached a maximum of $9.2 \times 10^{-2}$ compared to the original maximum of $7.3 \times 10^{-2}$, suggesting that the influence is small in this case.

Events in this study were related to AN reaction process equipment and are indicated by black hatching in the FT diagram (Fig. 8). Equipment improvement and/or introduction of safety protection measures were carried out for target events, with the failure rate being reduced from the perspective of reducing top event occurrence probability. 
The target event investment priority for reducing failure rate is indicated by the investment recovery year shown in Table 9. Table 9 details failure rates after equipment improvement or introducing safety protection measures. Data are from AN plant observations and data with no failure occurrence after remodeling are represented by an occurrence probability of $1.0 \times 10^{-5}$ (same as Table 8 ). In Table 9, top event occurrence probability is the value when each modification is done alone. Reduced displacement from the original top event occurrence probability is $\mathrm{d}$, and an improved loss amount is calculated as $\mathrm{d} \times$ (total loss amount).

Table 10 shows case study results when multiple modifications are performed simultaneously. In Case 1, modification with the relatively short investment recovery year in Table 9 is implemented, and Cases 2 to 4 add further modifications. In Table 10, $\bullet$ indicates implementation. Case 3 implementation reduces top event occurrence probability by the order of $10^{-5}$. Also, it can be implemented with a relatively short investment recovery year. Case 4 implementation is not a feasible safety investment, and we found that implementations up to Case 3 are sufficient.

Cases 3 and 4 differ in the absence or presence of sparger modification. From the perspective of improving loss amount, the investment effect of sparger modification cannot be seen. The sparger affects gas distribution in the fluidized bed and is thought to govern reaction efficiency in a fluidized bed reactor. Sparger modification is not an investment focusing on design optimization for safety purposes, but is rather an optimum design meant to improve reaction results. 
Table 9 Investment selection 1 . Reduced displacement from the original occurrence probability of the top event is $\mathrm{d}$, and $\mathrm{d} \times($ total loss amount) is calculated as the loss amount to be improved (Improvement). The investment priority is indicated by "Year to recovery investment".

\begin{tabular}{|c|c|c|c|c|c|c|c|c|c|}
\hline $\begin{array}{l}\text { Basic } \\
\text { event } \\
\text { No. }\end{array}$ & \multicolumn{2}{|c|}{ Facilities / Operation } & Failure & $\begin{array}{l}\text { Failure Rate or } \\
\text { Occurrence } \\
\text { Probability }\end{array}$ & Unit & $\begin{array}{l}\text { Top Event } \\
\text { Occurrence } \\
\text { Probability }\end{array}$ & $\begin{array}{l}\text { Investment } \\
\text { Myen }\end{array}$ & $\begin{array}{l}\text { Improvement } \\
\text { Myen }\end{array}$ & $\begin{array}{l}\text { Years to } \\
\text { Recover } \\
\text { Investment }\end{array}$ \\
\hline \multirow{4}{*}{ (6) } & \multirow{4}{*}{ Sparger } & & Crack (header) & $6.6 \mathrm{E}-07$ & $1 / \mathrm{h}$ & \multirow{2}{*}{-} & \multirow{2}{*}{-} & \multirow{2}{*}{-} & \multirow{2}{*}{-} \\
\hline & & & Crack (nozzles) & $3.4 \mathrm{E}-07$ & $1 / \mathrm{h}$ & & & & \\
\hline & & Modification 1 & Crack (header) & $1.7 \mathrm{E}-07$ & $1 / \mathrm{h}$ & \multirow{2}{*}{$6.8 \mathrm{E}-02$} & \multirow{2}{*}{280} & \multirow{2}{*}{4.3} & \multirow{2}{*}{65} \\
\hline & & Modification 2 & Crack (nozzles) & $1.0 \mathrm{E}-07$ & $1 / \mathrm{h}$ & & & & \\
\hline \multirow{3}{*}{ (7) } & \multirow{3}{*}{ Reactor } & & Undetected temperature abnormality & $3.0 \mathrm{E}-05$ & $1 / \mathrm{h}$ & - & - & - & - \\
\hline & & Modification 1 & \multirow[t]{2}{*}{ Undetected temperature abnormality } & $1.1 \mathrm{E}-05$ & $1 / \mathrm{h}$ & $4.5 \mathrm{E}-02$ & 35 & 24 & 1 \\
\hline & & Modification 2 & & $1.0 \mathrm{E}-05$ & $1 / 2$ years & $2.8 \mathrm{E}-02$ & 70 & 38 & 2 \\
\hline \multirow{2}{*}{ (8) } & \multirow{2}{*}{ Reactor } & & Leakage due to corrosion of condensed acidic material & 3.4E-07 & $1 / \mathrm{h}$ & - & - & - & - \\
\hline & & Modification & Leakage due to corrosion of condensed acidic material & $1.0 \mathrm{E}-05$ & $1 / 2$ years & $6.8 \mathrm{E}-02$ & 100 & 4.3 & 23 \\
\hline \multirow{5}{*}{ (9) } & \multirow{3}{*}{\multicolumn{2}{|c|}{ Cooling coils }} & Crack (welding part) & $1.0 \mathrm{E}-05$ & $1 / 2$ years & \multirow{3}{*}{-} & \multirow{3}{*}{-} & \multirow{3}{*}{-} & \multirow{3}{*}{-} \\
\hline & & & Crack (piping) & $1.0 \mathrm{E}-05$ & $1 / 2$ years & & & & \\
\hline & & & Crack (Reactor wall weld) & 7.3E-07 & $1 / \mathrm{h}$ & & & & \\
\hline & & Modification 1 & \multirow[t]{2}{*}{ Crack (Reactor wall weld) } & $1.3 \mathrm{E}-07$ & $1 / \mathrm{h}$ & $6.4 \mathrm{E}-02$ & 172 & 7.7 & 22 \\
\hline & & Modification 2 & & $1.0 \mathrm{E}-05$ & $1 / 2$ years & $6.3 \mathrm{E}-02$ & 264 & 9.3 & 29 \\
\hline \multirow[b]{2}{*}{ (17) } & \multirow[t]{2}{*}{ Reactor } & & Obstacles to fluidization & $1.0 \mathrm{E}+00$ & $1 / 2$ years & - & - & - & - \\
\hline & & Modification & Obstacles to fluidization & $1.0 \mathrm{E}-05$ & $1 / 2$ years & \multicolumn{4}{|c|}{$\begin{array}{l}\text { The cost and effect of fluidizing obstacle removal are } \\
\text { described in (19). }\end{array}$} \\
\hline \multirow{2}{*}{ (19) } & \multirow{2}{*}{ Reactor } & & Accumulation of Mo pieces & $9.7 \mathrm{E}-05$ & $1 / \mathrm{h}$ & - & - & - & - \\
\hline & & Modification & Accumulation of Mo pieces & $2.9 \mathrm{E}-06$ & $1 / \mathrm{h}$ & $6.3 \mathrm{E}-02$ & 40 & 9 & 4 \\
\hline \multirow{2}{*}{ (21) } & \multirow{2}{*}{ Reactor } & & Undetected hot spot & $1.2 \mathrm{E}-05$ & $1 / \mathrm{h}$ & - & - & - & - \\
\hline & & Modification & Undetected hot spot & $1.0 \mathrm{E}-05$ & $1 / 2$ years & $6.3 \mathrm{E}-02$ & 56 & 9 & 6 \\
\hline
\end{tabular}




\section{Discussion}

This study first revealed that in the AN process the reactor has the highest risk level. In general, the fluidized bed reaction has the advantages of uniform progress of the catalyst phase reaction, improved control of reaction temperature due to easy removal of heat, easy handling of gases with explosion range composition, and easy catalyst loading and unloading. Fluidized bed reaction systems are used in AN synthesis reactions and other commercial-scale chemical plants for these reasons. Many studies have focused on improving reaction yields by optimally controlling the partial oxidation reaction and improving the catalyst and equipment to improve economic efficiency, as noted in Section 2. Additionally, it is typically difficult to grasp the possibility of risk until an accident occurs in a fluidized bed reaction system as it is difficult to understand the accident occurrence mechanism. Because risk arises from nonlinear interactions between failures and/or normal operating fluctuations, it is difficult to think of ways to reduce risk.

Solving these issues requires comprehensive identification of such risks. In this study, we investigated and evaluated accident cases, reaction processes, plant components, natural disasters, and terrorist attacks that had not yet been considered for AN plants. Because the influences of natural disasters and terrorist attacks on chemical plants are not negligible, we regarded these influences as common faults.

From the evaluation of investment cost and benefits, the priority of single investment was shown initially (Table 9). Furthermore, to reduce fire/explosion risks, several investments were selected in order of high priority as single investments (Table 10). Because investment amounts and construction periods are limited in actual plants, it is believed that selecting investment destinations based on the method described in this study is sufficiently effective.

Table 10 Investment selection 2. Case study results when multiple modifications are performed at the same time. indicates implementation.

\begin{tabular}{|c|c|c|c|c|c|}
\hline Case & Investment & $\begin{array}{l}\text { Top Event } \\
\text { Occurrence } \\
\text { Probability }\end{array}$ & Investment & Improvement & $\begin{array}{l}\text { Years to } \\
\text { Recover } \\
\text { Investment }\end{array}$ \\
\hline & $\begin{array}{lllllll} & (6) & (7) & (8) & \text { (9) } & \text { (17) } & \text { (19) }\end{array}$ & $1 / 2$ years & Myen & Myen & Years \\
\hline 0 & & 7.3E-02 & - & - & - \\
\hline 1 & O & $1.7 \mathrm{E}-02$ & 166 & 48 & 3 \\
\hline 2 & 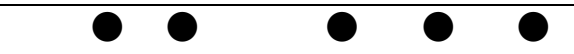 & $1.2 \mathrm{E}-02$ & 266 & 52 & 5 \\
\hline 3 & O & $3.1 \mathrm{E}-05$ & 530 & 62 & 9 \\
\hline 4 & O & $3.1 \mathrm{E}-05$ & 810 & 62 & 13 \\
\hline
\end{tabular}

100 yen $=1 \$$ 
Our study clearly demonstrates that risks related to fluidized bed reaction systems can be traced to specific equipment, subsystems, and operations. Thus, this study also demonstrated an effective method for reducing AN process risks by preventing certain operations or protecting against such risk events and finding safety investment priorities. However, this study has the following limitations.

(1) Estimating occurrence probability using an FT diagram

In this study, we calculated failure rates of specific components in the AN reaction process using data obtained from actual AN plants to determine top event occurrence probabilities. As noted above, failure rates of specific components in the AN reaction process are not available in the public literatures. Because failure rates can generally be obtained from statistical data, failure rate uncertainties are discussed here. In a discussion of blower failure rates, the Centralized Reliability Data Organization, established by the U.S. Department of Energy in 1985, found four distributions (normal distribution, exponential distribution, Weibull distribution, and lognormal distribution), and concluded that failure rates successfully fitted a lognormal distribution (Cadwallader et al., 1993). Since then, the lognormal distribution has been frequently applied to equipment failures. Because this study employed data from one AN plant, statistical fluctuation cannot be considered. Additionally, even if it were possible to collect data from several AN plants, it would be difficult to evaluate uncertainties in failure rates of AN reaction process components. This is because the design specifications of fluidized bed reactors, which have undergone refinement and improvement, are expected to be different in each plant. This stands in contrast with nuclear power plants, which have relatively unified equipment design.

The FT diagram also considered HEs, which at chemical plants typically include operating a valve in the wrong direction or overlooking signals. It was the case that reliability depended on random variables other than time. As noted in Section 4.2, we employed data on similar human error probabilities (HEP) obtained from the references (Gertman and Blackman, 1994; Williams, 1989). However, as expected, HEPs generally depend on plant operation; thus, further research using HEP data on AN plants is required.

(2) Safety investment selection

Because selecting combinations of multiple investments depends on top event occurrence probability, there might be priorities depending on the optimal combination that are not in accordance with the single investment rank order. However, in this study, we did not achieve this level of analysis.

To reduce risks associated with accidental fires and explosions at AN plants, this study clearly suggested a method for judging the importance of technical tasks. This method would allow engineers to notice the priority of technologies and provide a clear goal.

\section{Conclusions}

In this study, we evaluated a method for understanding safety investment priorities using risks in AN plants as an example. This study demonstrated that fires and explosions posed the greatest risks in the reaction 
process. As for the severity of the risk standard applied to AN plants, we proposed a modified index that considered both direct and indirect costs. By considering process characteristics and natural disasters, we added new accident scenarios and set up a policy to derive accident occurrence probabilities, develop accident prevention technical systems, and determine investment costs from FTAs. Our results highlighted safety protection equipment and investment costs. As a measure of the investment effect, the safety investment priority was indicated by using loss amount differences from before and after investment.

\section{Acknowledgments}

This study received funds from the Faculty of Environment and Information Sciences, the Yokohama National University.

\section{Conflict of interest}

The authors declare that there are no conflicts of interest.

\section{References}

Abuswer, M., Amyotte, P., Khan, F., 2013. A quantitative risk management framework for dust and hybrid mixture explosions. J. Loss Prevent. Proc. 26, 283-289.

Al-Sharrah, G.K., Edwards, D., Hankinson, G., 2007. A new safety risk index for use in petrochemical planning. Process Saf. Environ. 85. 533-540.

American Institute of Chemical Engineers (AIChE), 1994. Dow's Fire and Explosion Index Hazard Classification Guide, $7^{\text {th }}$ ed., AIChE, New York.

B. F. Goodrich Chemical Company, 1972. Acrylonitrile process analyzer system. Advan. Instrum. 27, 1-5.

Baybutt, P., 2018. Guidelines for designing risk matrices. Proc. Safety Prog. 37, 49-55.

Cadwallader, L.C., Taylor, G.L., 1993. Failure rate data for glovebox components and cleanup systems at the Tritium Systems Test Assembly. J. Fusion Energ. 12, 1-2. 
CCPS Process Safety Leading and Lagging Metrics, 2011. You Don't Improve What You Don't Measure, Retrieved January 2011.

https://www.aiche.org/sites/default/files/docs/pages/CCPS_ProcessSafety_Lagging_2011_2-24.pdf. (accessed 13 May 2019).

Centi, G., Perathoner, S., 1998. Unraveling a catalytic pathway: Acrylonitrile from propane. Chem. Tech. 28, 13-18.

Cox, L.A., 2008. What's wrong with risk matrices?. Risk Anal. 28, 497-512.

Cozzani, V., Smeder, M., Zanelli, S., 1998. Formation of hazardous compounds by unwanted reactions in industrial accidents. J. Hazard. Mater. A 63, 131-142.

Cruz, A.M., Krausmann, E., 2009. Hazardous-materials releases from offshore oil and gas facilities and emergency response following Hurricanes Katrina and Rita. J. Loss Prevent. Proc. 22, 59-65.

Curcurù, G., Galante, G.M., La Fata, C.M., 2013. An imprecise fault tree analysis for the estimation of the rate of occurrence of failure (ROCOF). J. Loss Prevent. Proc. 26, 1285-1292.

Dutta, S., Gualy, R., 1999. Overhaul process reactors. Hydrocarb. Process. 78, 43-50.

EPA, U.S., 1983. Health assessment document for acrylonitrile. (Final report No.EPA-600/8-82-007F).

EPA, U.S., 1998. Ambient Water Quality Criteria for the Protection of Human Health: Acrylonitrile. (EPA822-R-98-006).

Ferdous, R., Khan, F., Veitch, B., Amyotte, P.R., 2009. Methodology for computer aided fuzzy fault tree analysis. Process. Saf. Environ. 87, 217-226.

First, K., 2010. Scenario identification and evaluation for layers of protection analysis. J. Loss Prevent. Proc. 23, 705-718.

Gertman, D.I., Blackman, H.S., 1994. Human Reliability \& Safety Analysis Data Handbook, John Wiley \& Sons, Inc., New York.

Grasselli, R.K., 1986. Selective oxidation and ammoxidation of olefins by heterogeneous catalysis. J. Chem. Educ. 63, 216-229.

Grasselli, R.K., 1999. Advances and future trends in selective oxidation and ammoxidation catalysis. Catalysis Today. 49, 141-153.

Gu, Y., Chen, W., 1991. Separation of acrylonitrile and acetonitrile by xyren-water dual solvent extraction. Proc. Int. Conf. Pet. Refin. Petrochem. Process. 2, 552-558.

Guo, L., Kang, J., 2015. An extended HAZOP analysis approach with dynamic fault tree. J. Loss Prevent. Proc. $38,224-232$.

Hawkins, C., Wood, M., 1999. Slashing waste through tighter control. Chem. Eng. 106, 107.

Hopper, J.R., Yaws, C.L., Ho, T.C., Vichailak, M., 1993. Waste minimization by process modification. Waste Manag. 13, 3-14. 
IARC 1999. Monographs on the evaluation of carcinogenic risks to humans. 71, Re-Evaluation of Some Organic Chemicals, Hydrazine and Hydrogen Peroxide. Part I, 43-108.

ISO/TS 16901, 2015. Guidance of performing risk assessment in the design of onshore LNG installations including the ship/shore interface.

JANSI-CFR-02, 2016. Estimation of Domestic General Equipment Failure Rate Considering Uncertainty of Failure Number (1982-2010, 29 Years 56 Plants Data), June 2016.

www.genanshin.jp/archive/failure_rate/data/JANSI-CFR-02.pdf. (accessed 13 May 2019).

Kang, J., Guo, L., 2016. HAZOP analysis based on sensitivity evaluation. Saf. Sci. 88, 26-32.

Korkmaz, K.A., Sari, A., Carhoglu, A.I., 2011. Seismic risk assessment of storage tanks in Turkish industrial facilities. J. Loss Prevent. Proc. 24, 314-320.

Krausmann, E., Cruz, A.M., Affeltranger, B., 2010. The impact of the 12 May 2008 Wenchuan earthquake on industrial facilities. J. Loss Prevent. Proc. 23, 242-248.

Maccallion, J., 1996. New separation approach saves catalyst and energy. Chem. Process. 59, 73-74.

MacGregor, R.J., 2017. Results matter: three case studies comparing and contrasting PFFM and HazOp PHA reviews. J. Loss Prevent. Proc. 49, 266-279.

Miyake, A., Yamada, N., Ogawa, T., 2005. Mixing hazard evaluation of organic peroxides with other chemicals. J. Loss Prevent. Proc. 18, 380-383.

Pujado, P.R., 1977. Newest acrylonitrile process. Hydrocarb. Process. 56, 169-172.

Sanghavi, V.D., 1998. Pollution control and environmental protection in chemical industry. Chem. Eng. World. $33,61-62$.

Shah, S., Fischer, U., Hungerbühler, K., 2005. Assessment of chemical process hazards in early design stages. J. Loss Prevent. Proc. 18, 335-352.

Shelly, S., 1995. Catalytic oxidation unit meets stringent emission limits. Chem. Eng.. 102, 135.

TERA, 1997. Acrylonitrile Inhalation Cancer Risk Assessment.

Thanh-Binh, N., Dubois, J.L., Kaliaguine, S., 2016. Ammoxidation of acrolein to acrylonitrile over bismuth molybdate catalysts. Appl. Cat. A. 520, 7-12.

Van der Bann, H.S., 1980. The acrylonitrile process. NATO Adv. Study Inst. Ser. E 39, 522-533.

WHO. 1983. International Programme on Chemical Safety, Environmental Health Criteria 28, Acrylonitrile.

Williams, J.C., 1989. Human reliability data - the state of the art \& the possibility. in: Proc. Reliab. '89. UK, June 14/16. 1.

Yu, J., Cruz, A.M., Piatyszek, E., Lesbats, M., Tardy, A., Hokugo, A., Tatano, H., 2017. A survey of impact on industrial parks caused by the 2011 Great East Japan earthquake and tsunami. J. Loss Prevent. Proc. 50, $317-$ 324. 
Zhao, J., Cui, L., Zhao, L., Qiu, T., Chen, B., 2009. Learning HAZOP expert system by case-based reasoning and ontology. Comput. Chem. Eng. 33, 371-378.

\section{Figure captions}

Fig. 1 AN Process Flow.

Fig. 2 Top events. Events related to physical risk in an acrylonitrile plant reaction section. The top events identified are fire/explosion outside the reactor, fire/explosion inside the reactor, and reactor destruction.

Fig. 3 Identified events. Top events are derived from events caused by characteristics of partial oxidation reaction process obtained from actual plant operation. We obtained intermediate events for constructing accident scenarios and information to be considered as basic events from characteristics of equipment including fluidized bed reactors. Events that could be caused by natural disasters, cyber-attacks, or terrorism are positioned as causes of common failure, and thus would be related to all top events.

Fig. 4 System diagram of the accidents. Incidents can be accidents or disasters or can cause them, and it is possible to connect accidents and disasters with related incidents. Likewise, relevant incidents are also frequently connected with other incidents. Explosion and fire are mainly classified in a block with chemical reactions and destruction is mainly classified in a block with physical phenomena.

Fig. 5 Relationship between CCPS points and loss amounts. This figure shows the relationship between CCPS points and total loss amounts for the AN fluidized bed reactor accident case shown in Table 4.

Fig. 6 Relationship between revised CCPS points and loss amounts. This figure shows the relationship between the revised CCPS points and total loss amounts. 
Fig. 7 Revised CCPS points and loss amounts for three top events. The severity for three events is expressed using RCCPS points. In the pentagon graphs, the green, red, and blue lines represent the maximum, average, and minimum points, respectively. The loss amounts were calculated using the correlation formula in Fig. 6.

Fig. 8 Fault tree diagram (fire/explosion outside reactor). This is the fault tree diagram for the case of fire/explosion outside reactor. Green hatching indicates the occurrence probability of the basic event. Black hatching indicates events related to the equipment or phenomena of acrylonitrile reaction section.

\section{Table captions}

Table 1 Condition for acrylonitrile (AN) synthesis.

Table 2 Fire \& Explosion Index (F\&EI) risk rank.

Table 3 Fire \& Explosion Index (F\&EI) evaluation result.

Table 4 Examples of accidents in acrylonitrile fluidized bed reactors.

Table 5 Types of physical risks in acrylonitrile fluidized bed reactors.

Table 6 Center for Chemical Process Safety (CCPS) points.

Table 7 Revised Center for Chemical Process Safety (CCPS) points.

Table 8 Failure rate and occurrence probability. Failure rate unit is $1 /$ hour. Occurrence probability describes the probability of occurring within two years. 
Table 9 Investment selection 1. Reduced displacement from the original occurrence probability of the top event is $\mathrm{d}$, and $\mathrm{d} \times$ (total loss amount) is calculated as the loss amount to be improved (Improvement). The investment priority is indicated by "Year to recovery investment".

Table 10 Investment selection 2. Case study results when multiple modifications are performed at the same time. $\bullet$ indicates implementation. 